\title{
Do Long Memory and Asymmetries Matter When Assessing Downside Return Risk?
}

NICO KATZKE AND CHRIS GARBERS

\section{Stellenbosch Economic Working Papers: 06/15}

\section{KEYWORDS: VALUE-AT-RISK, EXPECTED SHORTFALL, GARCH, FRACTIONAL} INTEGRATION, KUPIEC BACK-TESTING PROCEDURE

JEL: C22, G13, G17

NICO KATZKE

DEPARTMENT OF ECONOMICS

UNIVERSITY OF STELLENBOSCH

PRIVATE BAG X1, 7602

MATIELAND, SOUTH AFRICA

E-MAIL: NICOKATZKE@SUN.AC.ZA
CHRIS GARBERS

DEPARTMENT OF ECONOMICS UNIVERSITY OF STELLENBOSCH

PRIVATE BAG X1, 7602

MATIELAND, SOUTH AFRICA

E-MAIL: 16294335@SUN.AC.ZA

A WORKING PAPER OF THE DEPARTMENT OF ECONOMICS AND THE BUREAU FOR ECONOMIC RESEARCH AT THE UNIVERSITY OF STELLENBOSCH 


\title{
Do Long Memory and Asymmetries Matter When Assessing Downside Return Risk?
}

\author{
Nico Katzke ${ }^{\mathrm{a}, *}$, Chris Garbers ${ }^{\mathrm{a}}$ \\ ${ }^{a}$ Department of Economics, Stellenbosch University, South Africa.
}

\begin{abstract}
In this paper we set out to test whether, on sector level, returns series in South Africa exhibit long memory and asymmetries and, more specifically, whether these effects should be accounted for when assessing downside risk. The purpose of this analysis is not to identify the most optimal downside risk assessment model or to reaffirm the often regarded stylized fact of long memory and asymmetry in asset returns series. Rather we set out to establish whether accounting for these effects and allowing for more flexibility in second order persistence models lead to improved risk assessments. We use several variants of the widely used GARCH family of second order persistence models that control for these effects, and compare the downside risk estimates using Value-at-Risk measures of these different models and compare their out-ofsample performances. Our findings confirm that controlling for asymmetries and long memory in volatility models improve risk management calculations.
\end{abstract}

Keywords:

Value-at-Risk, Expected Shortfall, GARCH, Fractional Integration, Kupiec back-testing procedure

JEL: C22, G13, G17

\section{Introduction}

The accurate measurement and management of measured risk exposure is of paramount importance to financial institutions and regulators alike. Although simple in construction and criticized after the global financial crisis

\footnotetext{
*Corresponding author

Email address: nicokatzke@sun.ac.za (Nico Katzke)
} 
as being ignorant of returns falling outside the normal spectrum, Value-atRisk (VaR hereafter) estimates of potential downside risk remain prevalent in the financial industry globally. It is used to evaluate the maximum potential loss that may ensue conditional on past information and premised typically on the assumption that returns are asymptotically normal. Despite serious shortcomings, VaR estimations remain a critical part of the tools used by practitioners and regulators in order to assess potential losses and make sufficient capital provisions to buffer such losses. Accuracy of these measures are important, as underestimating risk might lead to under-capitalized institutions and investors ignorant of true risk, while overestimating such risk might lead to inefficiencies. Estimates of future variability is also an important input into pricing derivatives.

The purpose of this paper is two-fold. Firstly, we test whether South African sector returns do exhibit significant asymmetries and long memory. Secondly, we test whether accounting for these effects produce superior outof-sample VaR forecast estimates, and thereby motivate its use in effectively managing downside risk. Our aim is therefore not solely to identify the model which provides the most accurate VaR estimates. Also, in contrast to most of the literature related to VaR estimation comparisons across different models, we apply the tests at sectoral level. The motivation for doing so follows in that inferences drawn from aggregate sector returns cannot necessarily be applied equally to assets across sectors. This is especially clear considering the great heterogeneity in terms of the data characteristics and distributions as summarized in table 1 . We then aggregate our findings using mean model rankings, which weighs equally the sector level results. The individual and collective results broadly support the hypothesis that sector level returns in South Africa do display significant asymmetries and long memory, and that accounting for these attributes leads to improved forecasts of downside risks.

The paper is organized as follows. We place the topic in context by referring to the most relevant literature in section 2, while section 3 outlines the approach that we take in answering the questions posed above. Section 4 then describes the data used and its characteristics, while section 5 discusses the results. Finally, we conclude the paper in section 6 . 


\section{Literature Overview}

\subsection{Background to using Value at Risk measures}

Standard portfolio theories are often attributed to the pioneering insights of Markowitz (1952) and subsequent authors that expanded on the basic fundamentals driving decision making processes in financial markets. In particular, the importance of the first two moments of assumed normal behaving returns became critical inputs in various measures aimed at guiding portfolio allocations and risk assessments in the proceeding decades. Since then, advances in computing power coupled with the fast pace of global financial intermediation causing great and opaque return interlinkages, both facilitated and necessitated the development of increasingly sophisticated methods of portfolio risk analysis. ${ }^{1}$ Despite the vast expansion of intricate risk assessment models, the evident misjudgment of risk exposure which contributed greatly to currency- and asset market crises in the late nineties and early 2000s, as well as the recent global financial crisis, provide testament to the great deficiencies remaining in even the most advanced risk models. Many have since argued for greater transparency in terms of communicating the shortcoming of such risk assessment models, while using indicators of risk that are more aligned with actual returns variability characteristics and are more robust to tail events (c.f. Giot and Laurent (2003a) and Degiannakis (2004) for more.).

Despite its shortcomings and criticisms, VaR has emerged as the benchmark estimate of portfolio risk as used by financial institutions and regulators (Engle and Manganelli, 2004). ${ }^{2}$ The widespread adoption of VaR by the financial industry stems from the fact that it is easy to interpret and calculate as well as allowing for aggregation across various trading positions to produce a single measure of risk exposure (Brooks and Persand, 2003). Value-at-risk can be described as the predicted amount of financial loss a portfolio could incur over a given time horizon and for a pre-defined confidence level.

${ }^{1}$ c.f. Engle and Manganelli (2004) and McMillan and Speight (2007) for more detail on the development of advanced techniques during this period.

${ }^{2}$ The Basel Committee on Banking Supervision still requires the use of VaR estimates (or more advanced derivatives thereof) in order to calculate the capital requirements of banks and investment firms. The 1995 amendment to the Basel Accord even allows the use of in-house econometric methodologies for VaR estimation purposes (on Banking Supervision, 1995, 1996)). 
Following the introduction of ARCH models by Engle (1982) and the generalization thereof in the GARCH framework of Bollerslev (1986), a rich variety of volatility models has emerged that can be used to describe the typically conditionally heteroskedastic returns dispersion. Modifications to deal with volatility asymmetries include the GJR-GARCH, EGARCH, and APARCH models, whilst specifications of the IGARCH and FIGARCH variety aim to address the volatility persistence, or strong memory, observed in second order moments of financial returns data (Engle and Bollerslev (1986); Nelson (1990); Glosten et al. (1993); Ding et al. (1993); Baillie et al. (1996)). The widely used RiskMetrics approach also allows for the modeling of $\sigma_{t}$ for the purposes of $\mathrm{VaR}$ estimation; however, as a result of calibration this method provides less flexibility during estimation (Giot and Laurent (2003a)).

Despite the fact that the majority of VaR studies mainly consider returns data from either the US, EU, or the Asia-Pacific region, several papers do include African financial markets in their analyses. In terms of the methodologies used, there is a clear benefit to accounting for deviations from normality as well as asymmetries and persistence in volatility modeling. In particular, Giot and Laurent $(2003 \mathrm{a}, \mathrm{b})$ find the APARCH with a skewed student t-distribution (skT) to provide the best VaR forecast when applied to both commodity- and US stock markets. Their findings suggest the use of the sKT distribution where the VaR for both short and long positions are required. Degiannakis (2004) provide similar evidence in this regard, concluding that the FIAPARCH with sKT is the most accurate when applied to UK, German, and French equity markets.

Angelidis et al. (2004)'s results also confirm the improved performance of volatility model VaR estimates when controlling for skew and leptokurtic distributions. Their results, however, indicate that a simple GARCH model produces superior results. Orhan and Köksal (2012) also show that simple specifications perform best when specifying forward VaR estimates. Their study compares 16 different GARCH specifications with the standard ARCH and t-distribution producing superior results. So and $\mathrm{Yu}$ (2006) also compare VaR forecast accuracies across 10 Asia-Pacific markets and 4 exchange rates. They also conclude in favor of student t-distributed (sT) errors as well as showing superior results from the GARCH, IGARCH and FIGARCH specifications. These recommendations are also echoed by McMillan and Speight (2007) and Thupayagale (2006), with Huang and Lin (2004) adding that asymmetries in returns also needs to be controlled for, with superior forecasts provided by the APARCH-sT specification. 
The studies of Bonga-Bonga and Mutema (2009), and McMillan and Thupayagale (2010) are of especial interest since these authors also focus only on South African financial market data. Bonga-Bonga and Mutema (2009) shows that the RiskMetrics specfications provide poor forecasting performance with regards to VaR estimation, and find that controlling for asymmetries via an EGARCH specification provide the best VaR results among the models considered in their paper. McMillan and Thupayagale (2010) also conclude the inferior estimates of VaR when using the RiskMetrics procedure. Furthermore, the authors show that controlling for volatility persistence in addition to asymmetries via the FIEGARCH model gives the most accurate VaR forecasts ${ }^{3}$.

Most of the studies cited above make use of aggregate indices such as the S\&P 500, JSE All-share, or FTSE 100 in their analyses. Our approach is to consider the forecast accuracy of VaR estimates on sector level, as we believe the aggregate indices may not reflect the need for asymmetric or long-memory models that control for non-normality in individual sector return series. At sector level, the measured returns dispersion, persistence in volatility and deviations from normal skewness and kurtosis differ significantly (as can be seen in table 1). As discussed in section 3, our choice of specification and estimation techniques affords comparability with the literature whilst the use of sector level data allows for judgment to be passed on the generalizability of previous VaR results. In line with the literature,we conclude that both at the individual sector level and on an aggregated basis, controlling for asymmetries and long memory in return volatility is important when estimating downside risks in asset returns series for South Africa. In contrast to several studies mentioned in this section that use skewed t-distributions, we find that GARCH and IGARCH models tend to perform poorly in out-of-sample forecasts relative to the more flexible models used in our study.

\section{Methodology}

A Value-at-Risk model can be defined as follows: Let $P_{t}$ denote the observed value of a portfolio of assets at time $t$, with $y_{t}=\log \left(P_{t} / P_{t-1}\right)$ denoting the continuously compounded logarithmic returns for the period $t-1$ to $t$.

\footnotetext{
${ }^{3}$ For the sake of brevity, we omit discussing the ARMA specification as the literature is well established on this front, see Enders (2010).
} 
Under the assumption that $y_{t} \sim \mathcal{N}(0,1)$, the Value-at-Risk for both long and short positions are the values, $\operatorname{Va} R^{(1-p)}$, such that:

$$
\begin{aligned}
& p_{\text {Long }}=P\left(y_{t} \leq V a R_{t}^{(1-p)}\right)=\int_{-\infty}^{V a R_{t}^{(1-p)}} \frac{1}{\sqrt{2 \pi}} \exp \left(-\frac{1}{2} y_{t}^{2}\right) d y_{t} \\
& p_{\text {Short }}=P\left(y_{t} \geq V a R_{t}^{(1-p)}\right)=\int_{V a R_{t}^{(1-p)}}^{+\infty} \frac{1}{\sqrt{2 \pi}} \exp \left(-\frac{1}{2} y_{t}^{2}\right) d y_{t}
\end{aligned}
$$

Implying that,

$$
\operatorname{VaR}_{t}^{(1-p)}=\zeta_{p}
$$

Where $\zeta_{p}$ is the $100 p^{t h}$ percentile of the standard normal distribution. A more generalized notation uses the case where $y_{t} \sim \mathcal{N}\left(\mu_{t}, \sigma_{t}^{2}\right)$. In this case we have (for the long position):

$$
p=P\left(y_{t} \leq V a R_{t}^{(1-p)}\right)=\frac{1}{\sigma_{t} \sqrt{2 \pi}} \int_{-\infty}^{V a R_{t}^{(1-p)}} \exp \left(-\frac{1}{2}\left(\frac{y_{t}-\mu_{t}}{\sigma_{t}}\right)^{2}\right) d y_{t} .
$$

From which we get the VaR as:

$$
\operatorname{VaR}_{t}^{(1-p)}=\mu_{t}+\zeta_{p} \cdot \sigma_{t}
$$

As a special case, the standard normal distribution of $y_{t}, V_{a} R^{(0.95)}$ would correspond to a VaR estimate of -1.645 . Given that the sample observations are captured at a daily level, this is equivalent to stating that we expect losses to exceed $1.645 \%$ on only 5 out of 100 days. Alternatively, we can say with $95 \%$ confidence that a portoflio of size $\$ 100000$ should not experience daily losses greater than $\$ 1645$ (Xekalaki and Degiannakis, 2010).

From equation 5, it is evident that VaR accuracy depends on accurate measurements of the following inputs. Firstly the mean process, $\mu_{t}$, and also the second order process, $\sigma_{t}$, and the characteristics of the distribution of returns, $\zeta_{t}$. Since financial time series data typically exhibit non-stationary first moments in addition to conditional heteroskedasticity, the parametric methodology often adopted for VaR estimates applies Box-Jenkins ARIMA mean equations with GARCH conditional heteroskedastic models (Xekalaki and Degiannakis (2010)). VaR estimates are then typically obtained in a twostep procedure where the first step concerns applying the ARIMA-GARCH 
framework to the simultaneous estimation of the mean $\left(\mu_{t}\right)$ and variance $\left(\sigma_{t}\right)$ processes. Thereafter, the empirical quantiles of $\zeta_{t}$ are calculated to produce the VaR estimates (Engle and Manganelli, 2004; Xekalaki and Degiannakis, 2010) $)^{4}$. It should also be noted that the VaR estimates defined above only indicate the potential loss at a specific level of confidence. This, however, says nothing about the expected loss faced when holding a portfolio. This clear shortcoming led to the development of the expected shortfall (ES) risk measure, which expresses the expected value of the loss contingent upon the VaR violation having occurred. Xekalaki and Degiannakis (2010) define ES as the "probalility-weighted average of tail loss and the one-step-ahead ES forecast." For long positions, ES can be expressed as follows:

$$
E S_{t+1 \mid t}^{(1-p)}=E\left[y_{t+1} \mid\left(y_{t+1} \leq V a R_{t+1 \mid t}^{(1-p)}\right)\right]
$$

If normality applies, the difference between the VaR and the ES estimate can be given as: $\operatorname{VaR}_{t}^{(0.95)}=-1.645$ and $E S_{t}^{(0.95)}=-2.061$, respectively. Thus at a $95 \%$ level of confidence, a portfolio of size $\$ 100000$ is predicted to lose $\$ 1645$ whilst the average daily loss given that a VaR violation occurs, is estimated at $\$ 2061$.

In order to facilitate comparibility with the literature, we will estimate the variance structure via a selection of models from the GARCH family. Specifically, our analysis will include the GARCH and IGARCH specifications as benchmarks against which to compare the performance of the GJR-GARCH, EGARCH, APARCH, FIGARCH, and FIAPARCH models ${ }^{5}$. Additionally, we will make use of the student-t distribution in all our model estimations due to its ability to consistently outperform VaR analyses underpinned by the normality assumption. ${ }^{6}$

We define the financial returns series for each individual sector as $y_{t}=$ $\log \left(P_{t} / P_{t-1}\right)$. Then, suppose $y_{t}$ follows the stochastic process:

$$
y_{t}=\mu_{t}+\varepsilon_{t}, \sim \mathcal{D}\left(0, \sigma_{t}^{2}\right)
$$

\footnotetext{
${ }^{4}$ During the estimation stage the modeller would have to select a distribution (normal, student-t, etc.) for $\zeta_{t}$.

${ }^{5}$ We omit RiskMetrics from our analysis given that it is nested within the IGARCH specification and has shown to produce poor VaR estimates due to its inherent inflexibility. C.f. Xekalaki and Degiannakis (2010); Bonga-Bonga and Mutema (2009).

${ }^{6}$ c.f. Giot and Laurent (2003b) for a deeper discussion into skewed t distributions for GARCH models and its superior performance compared to normally distributed models.
} 
Where $\mu_{t}=E\left(y_{t} \mid I_{t-1}\right), \sigma_{t}^{2}=E\left(\varepsilon_{t}^{2} \mid I_{t-1}\right)$ and $\mathcal{D}\left(0, \sigma_{t}^{2}\right)$ represents a conditional distribution with zero mean and variance of $\sigma_{t}^{2}$. Also, let $I_{t-1}$ denote the information set available at time $t-1$. As noted above, we apply the ARIMA framework in the estimation of $\mu_{t}$ with our real interest being the accurate modeling of the conditionally autocorrelated $\sigma_{t}$ process.

Following the notation proposed by Bollerslev (1986), the benchmark $\mathrm{GARCH}(\mathrm{p}, \mathrm{q})$ model can be represented as:

$$
\sigma_{t}^{2}=\alpha_{0}+\sum_{i=1}^{q} \alpha_{i} \varepsilon_{t-i}^{2}+\sum_{j=1}^{p} \beta_{j} \sigma_{t-j}^{2}
$$

The GARCH specification allows for both autoregressive and movingaverage components in the variance process. That is, the conditional variance of disturbances to the $y_{t}$ sequence constitutes an ARIMA process. Bollerslev (1986) also showed that the GARCH process of $y_{t}$ is covariance stationary if and only if $\sum_{i=1}^{q} \alpha_{i}+\sum_{j=1}^{p} \beta_{j}<0$, with $\alpha_{i}$ denoting news effects and $\beta_{j}$ corresponding to volatility persistence. The $\operatorname{IGARCH}(\mathrm{p}, \mathrm{q})$ model of Engle and Bollerslev (1986) is specified as in equation 8 with the added restriction that $\sum_{i=1}^{q} \alpha_{i}+\sum_{j=1}^{p} \beta_{j}=1$. This follows from the observation that many $\operatorname{GARCH}(1,1)$ models applied to returns data yield $\alpha_{1}+\beta_{1}$ values close to unity, implying highly persistent volatility. Thus, the IGARCH specification attempts to capture this volatility persistence by forcing the variance structure to behave like a unit root process (Enders (2010)).

Baillie, Bollerslev, and Mikkelsen (1996) subsequently extended the IGARCH model by allowing for fractional integration as opposed to integration of order one, providing a more flexible and convincing specification of the variance process. Suppose $\alpha(L)=\alpha_{1} L+\ldots+\alpha_{q} L^{q}$ and $\beta(L)=\beta_{1} L+\ldots+\beta_{p} L^{p}$, then $(1-\alpha(L)-\beta(L))=(1-L) \Psi(L)$, where $\Psi(L)$ represents all the roots outside the unit circle. By replacing the first difference operator $(1-L)$ with the fractional differencing operator $(1-L)^{d}$ and having $0<d<1$, we are left with the $\operatorname{FIGARCH}(p, d, q)$ model:

$$
\sigma_{t}^{2}=\alpha_{0}+\left(1-B(L)-\Phi(L)(1-L)^{d}\right) \varepsilon_{t}^{2}+B(L) \sigma_{t}^{2}
$$

If $d=1$ in equation 9 we are left with the $\operatorname{IGARCH}(\mathrm{p}, \mathrm{q})$ of Engle and Bollerslev (1986) while $d=0$ corresponds to the $\operatorname{GARCH}(\mathrm{p}, \mathrm{q})$ specification. The benfit of allowing $0<d<1$ as opposed to forcing $d=0$ or $d=1$, lies in the fact that shocks decay at a slow, hyperbolic rate compared to the 
exponential decay witnessed in GARCH models or the permanent residual impact in IGARCH models. This affords the modeling of fatter tails (long memory) without the need for restrictive assumptions regarding the volatility process.

Apart from volatility persistence in the form of long memory, there is also evidence of asymmetry in the response of second order persistence models to respectively negative and positive return disturbances (Giot and Laurent (2003a)). In attempting to deal with this asymmetric impact, the GJRGARCH(p,q) specification of Glosten, Jagannathan, and Runkle (1993) provides a simple and easily interpretable method of dealing with asymmetric residual responses on volatility persistence. It can be written as:

$$
\sigma_{t}^{2}=\alpha_{0}+\sum_{i=1}^{q}\left(\alpha_{i} \varepsilon_{t-i}^{2}\right)+\sum_{i=1}^{q}\left(\gamma_{i} I\left(\varepsilon_{t-i}<0\right) \varepsilon_{t-i}^{2}\right)+\sum_{j=1}^{p}\left(\beta_{j} \sigma_{t-j}^{2}\right)
$$

with $I\left(\varepsilon_{t-i}<0\right)$ denoting an indicator variable which takes on a value of unity if $\varepsilon_{t-i}$ is negative, and zero if positive. The GJR-GARCH model therefore allows the presence of leverage effects in return volatility, with positive disturbances impacting second order persistence by $\alpha_{1}$, while conversely the impact of negative shocks is given by $\alpha_{1}+\gamma_{1}$. For $\gamma_{i}>0$.

Nelson (1991)'s EGARCH(p,q) model is also often used as an alternative model to the simpler GJR-GARCH specification in equation 10. It takes the following form:

$$
\begin{aligned}
\ln \left(\sigma_{t}^{2}\right)= & \alpha_{0}+\left(1+\sum_{i=1}^{q} \alpha_{i} L^{i}\right)\left(1-\sum_{j=1}^{p} \beta_{j} L^{j}\right)^{-1} \\
& \times\left(\gamma_{1} \frac{\varepsilon_{t-1}}{\sigma_{t}}+\gamma_{2}\left[\left|\frac{\varepsilon_{t-1}}{\sigma_{t}}\right|-E\left(\frac{\varepsilon_{t-1}}{\sigma_{t}}\right)\right]\right)
\end{aligned}
$$

The inclusion of $\left|\frac{\varepsilon_{t-1}}{\sigma_{t}}\right|$ and $\frac{\varepsilon_{t-1}}{\sigma_{t}}$ above allow for $\sigma_{t}^{2}$ to be asymmetrically distributed. Specifically, $\gamma_{1}$ gives the sign effect whilst $\gamma_{2}$ shows the magnitude effect. Thus, $\gamma_{1}<0$ will indicate the presence of leverage effects (Xekalaki and Degiannakis, 2010). The benefit of the specification in equation 11 is that it allows both the level and sign of shocks to impact second order persistence, as well as relaxing the strict positive definite restrictions applied to standard GARCH equations listed above. 
Another popular GARCH type model proposed by Ding et al. (1993), which takes a different approach to controlling for asymmetries, is the APARCH model. It can be written as:

$$
\sigma_{t}^{\delta}=\alpha_{0}+\sum_{i=1}^{q} \alpha_{i}\left|\varepsilon_{t-1}\right|-\gamma_{i} \varepsilon_{t-i}^{\delta}+\sum_{j=1}^{p} \alpha_{j} \sigma_{t-j}^{\delta}
$$

The APARCH model above imposes a Box-Cox citepbox1964 power transformation on the conditional standard deviation process and the asymmetric absolute innovations (Xekalaki and Degiannakis (2010)). As $\delta \rightarrow 1$, the longer the memory process is, while $-1<\gamma_{i}<1$ reflects a leverage effect. As in the GJR-GARCH model, a positive value for $\gamma_{i}$ means that past negative shocks impact current conditional volatility stronger than past positive shocks. Furthermore, the APARCH specification nests several other volatility models. For example, $\delta=2 \& \gamma_{i}=0$ corresponds to a GARCH specification, while $\delta=2$ gives the GJR-GARCH. Finally, one can also combine the FIGARCH and APARCH models to form the $\operatorname{FIAPARCH}(\mathrm{p}, \mathrm{d}, \mathrm{q})$ model, as suggested by Tse (1998):

$$
\sigma_{t}^{\delta}=\alpha_{0}+\left(1-(1-B(L))^{-1} \Psi(L)(1-L)^{d}\right)\left(\left|\varepsilon_{t}\right|-\gamma \varepsilon_{t}\right)^{\delta}
$$

Here $\gamma$ accounts for asymmetries and $\delta$ allows for volatility persistence, or long memory. The amalgamation of the FIGARCH and APARCH specifications provide a flexible estimation procedure. This stems from the fact that one can allow for shocks to die out hyperbolically as opposed to exponentially or indefinitely, while also including the importance of sign effects in the analysis (Degiannakis (2004)).

The next step in our analysis is then to evaluate the accuracy of each model specification in terms of its VaR estimates. In order to achieve this, we make use of two widely used backtests, namely the Kupiec (1995) backtesting and the Engle and Manganelli (2004) DQ test. The goal of these tests are to test the null hypothesis that a given model's VaR estimate correctly approximates the conditional quantile for a specified probability threshold level. For Kupiec (1995)'s non-parametric back-test, the objective is to determine whether the percentage of VaR violations exceeds the VaR estimate suggested by each model. Thus if we let $N=\sum_{t=1}^{\tilde{T}} \tilde{I}_{t}$ be the number of trading days over the $\tilde{T}$ period that a portfolio of assets exceeds the VaR 
estimate $^{7}$, where:

$$
\tilde{I}_{t+1}= \begin{cases}1, & \text { if } y_{t+1}<\operatorname{Va} R_{t+1 \mid t}^{(1-p)} \\ 0, & \text { if } y_{t+1} \geq V a R_{t+1 \mid t}^{(1-p)}\end{cases}
$$

the coverage ratio is given as $N / \tilde{T}$, allowing us to test the following hypotheses:

$$
H_{0}: p^{*}=p, \quad H_{1}: p^{*} \neq p
$$

Here $p$ is the expected percentage of VaR violations and $p^{*}$ is the true percentage of violations (Kupiec, 1995). The test assumes the violations are driven by a Binomial distribution, and the $H_{0}: p=p^{*}$ is evaluated using an unconditional coverage test (LR test).

Engle and Manganelli (2004) propose a different statistical test that we will also provide in the results section. Their method is to construct the random variable $H i t_{t+1}=\tilde{I}_{t+1}-p$ and test whether it is uncorrelated with its own lagged values in addition to the VaR forecast and forecast lags. This procedure is represented by the Dynamic Quantile (DQ) test below.

$$
H i t_{t}=\sum_{i=1}^{i^{\prime}} X_{t-i}=\delta_{0}+\sum_{i=1}^{i^{\prime}} \delta_{i} H i t_{t-i}+\sum_{j=1}^{j^{\prime}} \varphi_{j} V a R_{t-j+1 \mid t-j}^{(1-p)}+\varepsilon_{t}
$$

The null is that $\mathrm{Hit}_{t}$ is orthogonal to the lags specified above, with the statistic used in the evaluation of equation 15 following a $\chi_{q}^{2}$, with $q=\operatorname{rank}\left(X_{t}\right)$ (see Engle and Manganelli (2004) for more details on estimation procedures). Although several other back-tests exist (c.f. Christoffersen and Pelletier (2004) and Haas (2005) for duration based VaR testing procedures), Berkowitz, Christoffersen, and Pelletier (2011) show convincingly, using Monte-Carlo simulations, that the misspecified VaR tests used in this study produce more reliable tests than other back-testing procedures.

In section 5, both the Kupiec (1995) Failure Rate (FR) and the DQ tests will be used to evaluate the accuracies of both the VaR and ES forward estimates from the models discussed in this section.

\footnotetext{
${ }^{7}$ In defining this test here, we assume a long trading position. The converse applies similarly.
} 


\section{Data Description}

This paper makes use of daily data from the 8 main economic sectors of the JSE All Share Index (ALSI) as defined by the Global Industry Classification Standard (GICS). The data was obtained from Bloomberg for the period 4 January 2000 until 16 January 2015, with a total of 4763 observations per series ${ }^{8}$. An index was constructed for each sector with daily market capitalization used to generate individual share weightings for inclusion into each specified sector. We generate the return series as specified in equation 7 , with $y_{t}=\log \left(P_{t} / P_{t-1}\right)$. The 8 sectors to be utilized are as follows:

1. Consumer Staples - labelled as DL_CONSS (13 assets)

2. Consumer Discretionary - labelled as DL_CONSD (18 assets)

3. Health - labelled as DL_HEALTH (3 assets)

4. Financials - labelled as DL_FINI (32 assets)

5. Industrials - labelled as DL_INDI (18 assets)

6. Energy - labelled as DL_ENERGY (3 assets)

7. Telecommunications - labelled as DL_TELECOMM (2 assets)

8. Information Technology - labelled as DL_IT (3 assets)

Table 1 below provides some descriptive statistics on the data. The difference in sample size for the CONSD and IT series stem from insufficient market capitalization data being available prior to 2002. From the table, one can see a large degree of homogeneity in characteristics across the various series. For instance, all the returns are either positively or negatively skewed in addition to displaying excess kurtosis. This is echoed by the Jarque-Bera test statistic which rejects the null of normality at a confidence level of both $99 \%$ and $95 \%$. Thus, our use of the student-t distribution in the volatility persistence equations specificatied is warranted. Furthermore, the Robust $Q^{2}(10)$ statistics confirm the presence of serial correlation in all of the second order disturbances, supporting the application of the GARCH framework.

\footnotetext{
${ }^{8}$ For the Consumer Discretionary and Telecommunications sectors, the data spans from 3 January 2002 to 16 January 2015.
} 
Table 1: Dataset Characteristics

\begin{tabular}{|c|c|c|c|c|c|c|c|c|}
\hline \hline & DL_CONSD & DL_CONSS & DL_HEALTH & DL_FINI & DL_INDI & DL_ENERGY & DL_IT & DL_TCOMM \\
\hline Standard Deviation & 0.020726 & 0.016418 & 0.018501 & 0.017791 & 0.017152 & 0.02193 & 0.023929 & 0.023753 \\
Skewness & 0.12571 & 0.14375 & 0.35178 & -3.829 & -0.5008 & 0.04131 & -0.33014 & 1.6673 \\
Excess Kurtosis & 2.8365 & 2.8523 & 4.7343 & 78.821 & 9.6088 & 2.8037 & 7.1399 & 30.847 \\
Jarque-Bera & 1100.4 & 1286.2 & 3588 & $9.8227 e^{5}$ & 14618 & 1232.3 & 6979.5 & $1.5078 e^{5}$ \\
Minimum & -0.091119 & -0.080298 & -0.094313 & -0.39719 & -0.21484 & -0.11182 & -0.22506 & -0.1277 \\
Maximum & 0.13707 & 0.10231 & 0.16647 & 0.11016 & 0.13764 & 0.11854 & 0.16156 & 0.42542 \\
Robust $Q^{2}(10)$ & 27.0049 & 21.0768 & 22.2528 & 18.0632 & 19.717 & 33.6759 & 17.2128 & 40.9578 \\
$\quad \mathrm{~N}$ & 3257 & 3759 & 3759 & 3759 & 3759 & 3759 & 3258 & 3759 \\
\hline
\end{tabular}

The characteristics of these series can also be confirmed by viewing figures A.1 to A.8 in the appendix. The figures show the daily returns of the assets in the individual sectors to have leptokurtic distributions with fat tails. The volatility clustering in the daily returns of each sector series is clearly visible. The QQ-plots also show the presence of fat-tailed distributions and asymmetric dispersion for all the sector returns data. The evidence therefore advocates the use of volatility specifications such as the IGARCH, GJR-GARCH, EGARCH, APARCH, FIGARCH, and FIAPARCH in order to take account of these data characteristics. Apart from the deviations from normality as shown by the Jarque-Bera statistic, the fat-tailed distributions observed in our return series further complements the use of the student-t distribution in our analysis.

\section{Results}

For each index defined in section 4, we calculated the out-of-sample VaR estimates using the G@RCH package of Laurent and Peters (2002). Outof-sample estimates are the most relevant from a practical perspective, as it reflects the accuracy of the VaR measures in the same way as VaR estimates would be used on a daily basis by financial institutions. As per Thupayagale (2006), McMillan and Speight (2007), and McMillan and Thupayagale (2010) we utilize the last five years of data for the purposes of out-of-sample forecasting. In doing so, we also re-estimate parameters every 50 days. In generating VaR estimates, we will focus on the $95 \%, 97.5 \%$, and $99 \%$ quantiles of the error distribution. For the purpose of this analysis, we choose an 
$\operatorname{ARMA}(2,0)$ specification for the mean equations, and estimate $\operatorname{GARCH}(1$, 1), $\operatorname{IGARCH}(1,1), \operatorname{GJR}-\operatorname{GARCH}(1,1), \operatorname{EGARCH}(1,1), \operatorname{APARCH}(1,1)$, $\operatorname{FIGARCH}(1,1)$ and $\operatorname{FIAPARCH}(1,1)$ models for the variance processes. ${ }^{9}$

Our results reveal a significant degree of second order persistence in each series, as evidenced by statistically significant ARCH and GARCH effects ${ }^{10}$. All of our models adhere to the necessary restrictions, namely the positivity constraints as well as the constraints relating to moment existence ${ }^{11}$. As shown by the Dynamic Quantile (denoted DQ) test statistics in tables A.4 to A.11 in the Appendix, the majority of the models reject the presence of remaining serial correlation for both long and short positions at all confidence levels ${ }^{12}$. Additionally, there is a tendency to underestimate risk for short positions and to overestimate risk for long positions, evidenced by the Kupiec (1995) failure rates (denoted FR) in tables A.4 to A.11. Unsurprisingly, the expected shortfall (denoted ES) measure strongly depends on both the trading position (long vs. short) and the chosen sector. The results, however, show these values as being relatively robust to specification changes to the ES for each trading position, remaining relatively constant across models within each sector.

Using the output contained in tables A.4 to A.11, we constructed tables A.12 to A.18 which contain each model's rank per sector in terms of the failure rate (FR). Abbreviated discussions of the individual findings related to each sector are contained in the appendix for the sake of brevity. The sector level information was then used to construct table 2, which shows the average rank of each model across all indices and confidence levels. From our results it is clear that both the sector level- and the aggregated findings suggest a clear benefit to increased second order specification flexibility. Both show that models which allow for the volatility process to be characterized by asymmetries and/or long memory consistently outperform other varieties.

\footnotetext{
${ }^{9}$ The ARMA $(2,0)$ specification was chosen according to the Box-Jenkins methodology whilst the volatility specifications are in keeping with the literature (c.f. Enders (2010) for a summary on the appropriateness of the GARCH specifications used.

${ }^{10}$ For the sake of brevity, we omit reporting the parameter coefficients here. Please contact the authors for the estimation output.

${ }^{11}$ All of our models achieved convergence except for the $\operatorname{IGARCH}(1,1)$ model of the Information Technology Index.

${ }^{12}$ This does not hold for the energy, information technology, and telecommunications series where some of the specifications fail to reject the null hypothesis of the DQ test.
} 
This conclusion stems from the fact that at each trading position and level of confidence, table 2 consistently shows the top 2 models as being either asymmetric or long memory in nature, or a combination of the two. It is also interesting to note that the benchmark GARCH and IGARCH models consistently fall in the lower half of the ranking distribution. In the case of the IGARCH, this clearly reveals the risk of imposing a specific structure on the variance process as opposed to allowing the data to carry more weight as in the FIGARCH specification ${ }^{13}$.

Our results thus strongly advocate the use of volatility models which account for non-normality, skewness of returns and long memory in second order persistence when evaluating downside return risks for South African firms. Our sector level aggregated findings are generally consistent with the literature, although we find (in contrast to several other papers) the standard GARCH model to be consistently less accurate at specifying VaR estimates, despite using the skewed Student t-distribution ${ }^{14}$. Generally, we find variation in the distributional characteristics and subsequent VaR forecast accuracy results for the individual sectors, motivating our use of sector level data as opposed to focussing solely on the aggregated index. Despite the heterogeneity, our results hold that, on aggregate, accounting for the volatility characteristics listed in the paper matter for achieving more accurate downside risk estimates.

\footnotetext{
${ }^{13}$ Although more flexible than the RiskMetrics specification, the IGARCH still nests the assumption of a variance process that is integrated of order one Xekalaki and Degiannakis (2010).

${ }^{14}$ As mentioned in section 2, several papers find the skewed-T-GARCH(1,1) model to provide accurate forward estimates of VaR relative to other, more flexible GARCH models as used in our study.
} 
Table 2: Summary of VaR Results

\begin{tabular}{|c|c|c|c|c|c|c|}
\hline \multirow[b]{3}{*}{ Model } & \multicolumn{6}{|c|}{ Average model rank across all sectors } \\
\hline & \multicolumn{3}{|c|}{ Short Positions } & \multicolumn{3}{|c|}{ Long Positions } \\
\hline & 0.95 & 0.975 & 0.99 & 0.95 & 0.975 & 0.99 \\
\hline $\operatorname{GARCH}(1,1)$ & 7 & 3 & 6 & 6 & 5 & 6 \\
\hline $\operatorname{IGARCH}(1,1)$ & 5 & 4 & 5 & 4 & 7 & 7 \\
\hline GJR-GARCH $(1,1)$ & 6 & 7 & 3 & 7 & 6 & 4 \\
\hline EGARCH $(1,1)$ & 1 & 2 & 4 & 1 & 1 & 5 \\
\hline $\operatorname{APARCH}(1,1)$ & 4 & 6 & 6 & 5 & 3 & 3 \\
\hline FIGARCH $(1,1)$ & 2 & 1 & 1 & 3 & 1 & 1 \\
\hline FIAPARCH $(1,1)$ & 3 & 4 & 2 & 2 & 4 & 2 \\
\hline
\end{tabular}

Specifications are ranked according to the average Kupiec (1995) test results across all sectors. See tables A.4 to A.11 for estimation output per sector and tables A.12 to A.18 for the ranking of each model per sector.

\section{Conlusion}

The purpose of this paper is to study whether, on sector level, returns series in South Africa exhibit long memory and asymmetries and, more specifically, whether these effects should be accounted for when assessing downside risk. The purpose of this analysis is not to identify the most optimal downside risk assessment model or to identify the presence of long memory and asymmetry in asset returns series. Rather we set out to establish a more general finding of whether accounting for these effects in second order persistence models lead to improved risk assessment forecasts. To achieve this, we fitted several GARCH type models with different features and levels of complexity to the studied returns series. We then proceeded to forecast the 
Value-at-Risk and Expected Shortfall estimates using a moving window estimation procedure. We then used two prominent back-testing procedures, namely the Kupiec (1995) Failure Rate statistic and the Engle and Manganelli (2004) Dynamic Quantile tests to compare the out-of-sample performance of the different volatility models. Despite some heterogeneity between sectors in terms of the ranking performance of the different volatility models, our results broadly confirm our stated hypotheses. In particular, we find strong evidence that controlling for leverage effects in volatility modelling, as well as accounting for long-memory in the second order moment process, significantly and consistently improve VaR forecast accuracy. Collectively, this implies that regulators and portfolio managers should consider using volatility models that do control for these effects in order to improve downside risk estimates. This is important to ensure that risk estimates are accurately calculated so as to ensure that appropriate levels of capital are held to offset potential losses.

\section{References}

Angelidis, T., A. Benos, and S. Degiannakis (2004). The use of GARCH models in var estimation. Statistical Methodology 1(1), 105-128.

Baillie, R. T., T. Bollerslev, and H. O. Mikkelsen (1996). Fractionally integrated generalized autoregressive conditional heteroskedasticity. Journal of econometrics $74(1), 3-30$.

Berkowitz, J., P. Christoffersen, and D. Pelletier (2011). Evaluating value-atrisk models with desk-level data. Management Science 57(12), 2213-2227.

Bollerslev, T. (1986). Generalised autoregressive conditional heteroscedasticity. Journal of Econometrics (31), 307-327.

Bonga-Bonga, L. and G. Mutema (2009). Volatility forecasting and valueat-risk estimation in emerging markets: the case of the stock market index portfolio in south africa. South African Journal of Economic and Management Sciences (12), 401-411.

Brooks, C. and G. Persand (2003). Volatility forecasting for risk management. Journal of Forecasting 22(1), 1-22. 
Christoffersen, P. and D. Pelletier (2004). Backtesting value-at-risk: A duration-based approach. Journal of Financial Econometrics 2(1), 84108.

Degiannakis, S. (2004). Volatility forecasting: Evidence from a fractional integrated asymmetric power arch skewed-t model. Applied Financial Economics 14 (18), $1333-1342$.

Ding, Z., C. W. Granger, and R. F. Engle (1993). A long memory property of stock market returns and a new model. Journal of Empirical Finance 1(1), $83-106$.

Enders, W. (2010). Applied Econometric Time Series (3 ed.). United States of America: John Wiley \& Sons.

Engle, R. F. (1982). Autoregressive conditional heteroscedasticity with estimates of the variance of united kingdom inflation. Econometrica 50(4), 987-1007.

Engle, R. F. and T. Bollerslev (1986). Modelling the persistence of conditional variances. Econometric Reviews 5(1), 1-50.

Engle, R. F. and S. Manganelli (2004). Caviar: Conditional autoregressive value at risk by regression quantiles. Journal of Business \&6 Economic Statistics 22(4), 367-381.

Giot, P. and S. Laurent (2003a). Market risk in commodity markets: a VaR approach. Energy Economics 25(5), 435 - 457.

Giot, P. and S. Laurent (2003b). Value-at-risk for long and short trading positions. Journal of Applied Econometrics 18(6), 641-663.

Glosten, L. R., R. Jagannathan, and D. E. Runkle (1993). On the relation between the expected value and the volatility of the nominal excess return on stocks. The Journal of Finance 48(5), 1779-1801.

Haas, M. (2005). Improved duration-based backtesting of value-at-risk. Journal of Risk 8(2), 17-38.

Huang, Y. and B.-J. Lin (2004). Value-at-risk analysis for taiwan stock index futures: Fat tails and conditional asymmetries in return innovations. Review of Quantitative Finance and Accounting 22(2), 79-95. 
Kupiec, P. (1995). Techniques for verifying the accuracy of risk measurement models. Journal of Derivatives 3, 73-84.

Laurent, S. and J. Peters (2002). G@RCH 2.2: An Ox package for estimating and forecasting various arch models. Journal of Economic Surveys 16, $447-485$.

Markowitz, H. (1952). Portfolio Selection. The Journal of Finance 7(1), $77-91$.

McMillan, D. and P. Thupayagale (2010). Evaluating stock index return value-at-risk estimates in south africa: Comparative evidence for symmetric, asymmetric and long memory GARCH models. Journal of Emerging Market Finance 9(3), 325-345.

McMillan, D. G. and A. E. H. Speight (2007). Value-at-risk in emerging equity markets: Comparative evidence for symmetric, asymmetric, and long-memory GARCH models. International Review of Finance 7(1-2), $1-19$.

Nelson, D. B. (1990). Stationarity and persistence in the GARCH(1,1) model. Econometric Theory 6(3), 318-334.

Nelson, D. B. (1991). Conditional heteroskedasticity in asset returns: A new approach. Econometrica 59(2), 347-370.

on Banking Supervision, B. C. (1995). An Internal Model-Based Approach to Market Risk Capital Requirements. Basel: BIS.

on Banking Supervision, B. C. (1996). Supervisory Framework for the Use of 'Backtesting' in Conjunction with the Internal Model-Based Approach to Market Risk Capital Requirements. Basel: BIS.

Orhan, M. and B. Köksal (2012). A comparison of GARCH models for var estimation. Expert Systems with Applications 39(3), 3582-3592.

So, M. K. and P. L. Yu (2006). Empirical analysis of GARCH models in value at risk estimation. Journal of International Financial Markets, Institutions and Money 16(2), $180-197$. 
Thupayagale, P. (2006). Evaluation of GARCH-based models in value-at-risk estimation: Evidence from emerging equity markets. Investment Analysts Journal (72), 13 - 29.

Tse, Y. K. (1998). The conditional heteroscedasticity of the yen-dollar exchange rate. Journal of Applied Econometrics 13(1), 49-55.

Xekalaki, E. and S. Degiannakis (2010). ARCH Models for Financial Applications. West Sussex: John Wiley \& Sons. 


\section{Appendix A. Figures and Tables}

Figure A.1: Consumer Discretionary Index in level, daily returns, daily returns density (versus normal) and QQ-plot against the normal distribution.

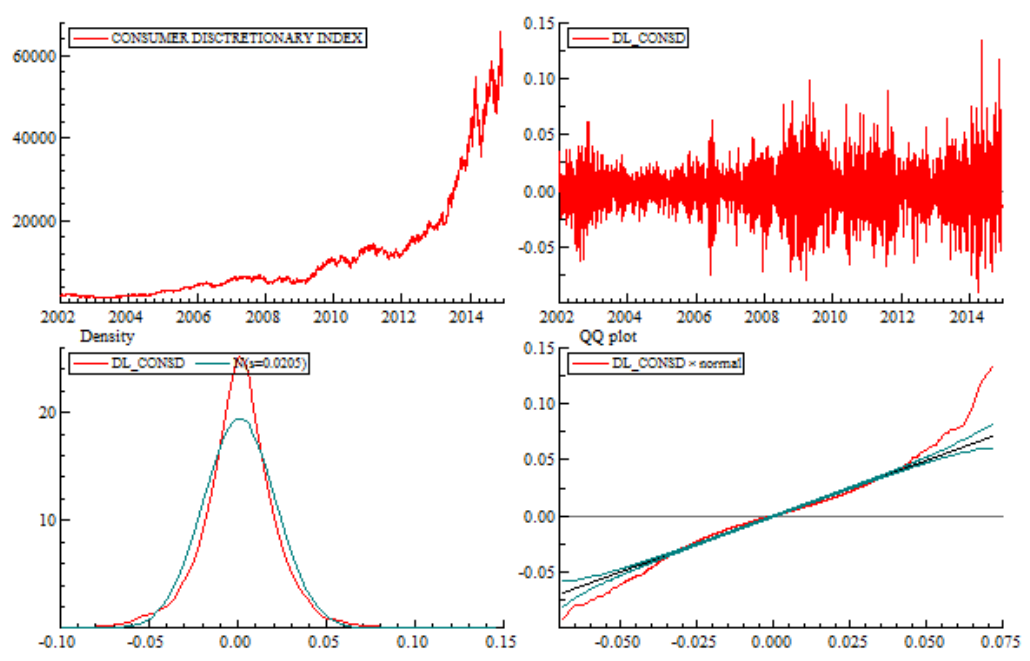

Figure A.2: Financials Index in level, daily returns, daily returns density (versus normal) and QQ-plot against the normal distribution.
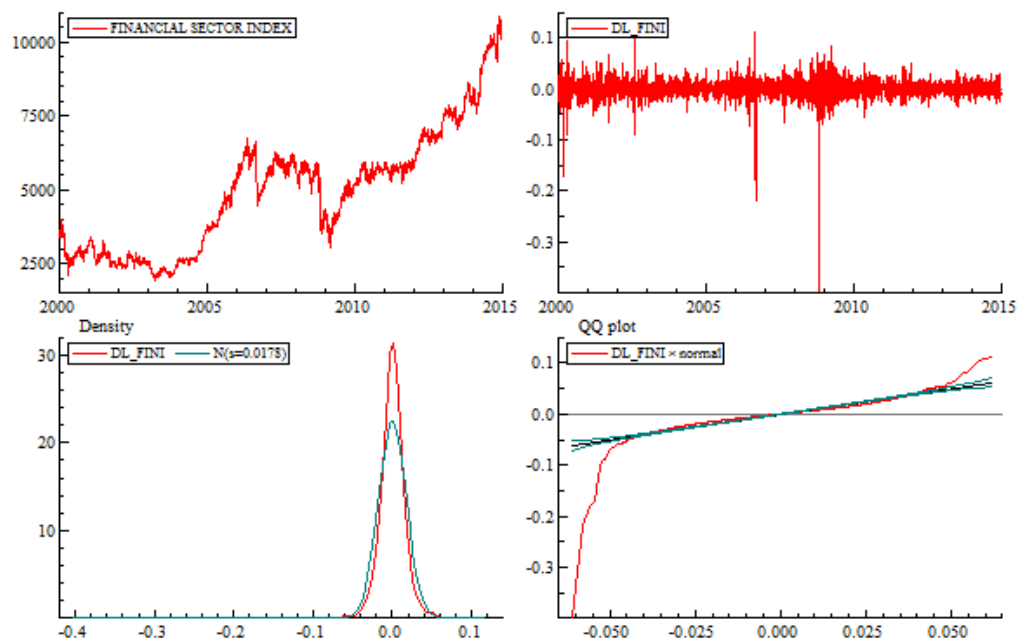
Figure A.3: Energy Index in level, daily returns, daily returns density (versus normal) and QQ-plot against the normal distribution.
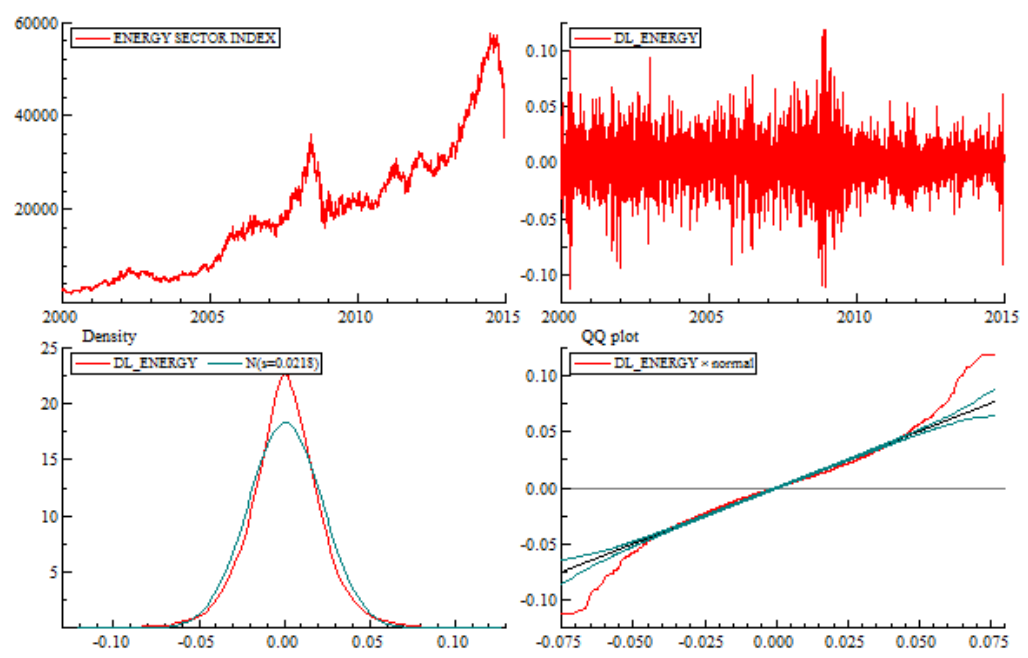

Figure A.4: Consumer Staples Index in level, daily returns, daily returns density (versus normal) and QQ-plot against the normal distribution.

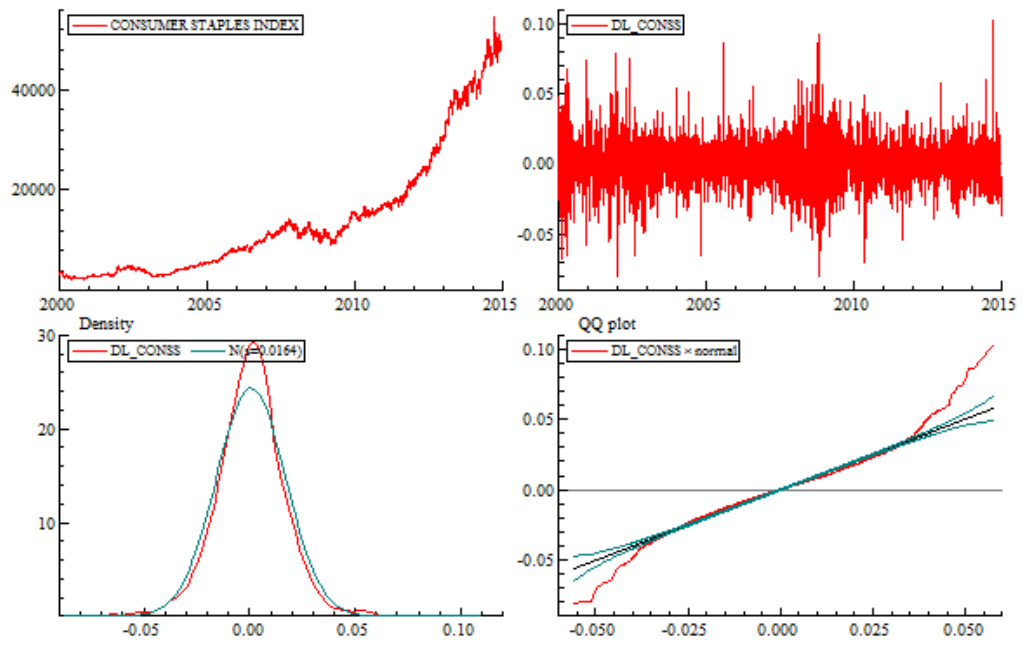


Figure A.5: Health Index in level, daily returns, daily returns density (versus normal) and QQ-plot against the normal distribution.
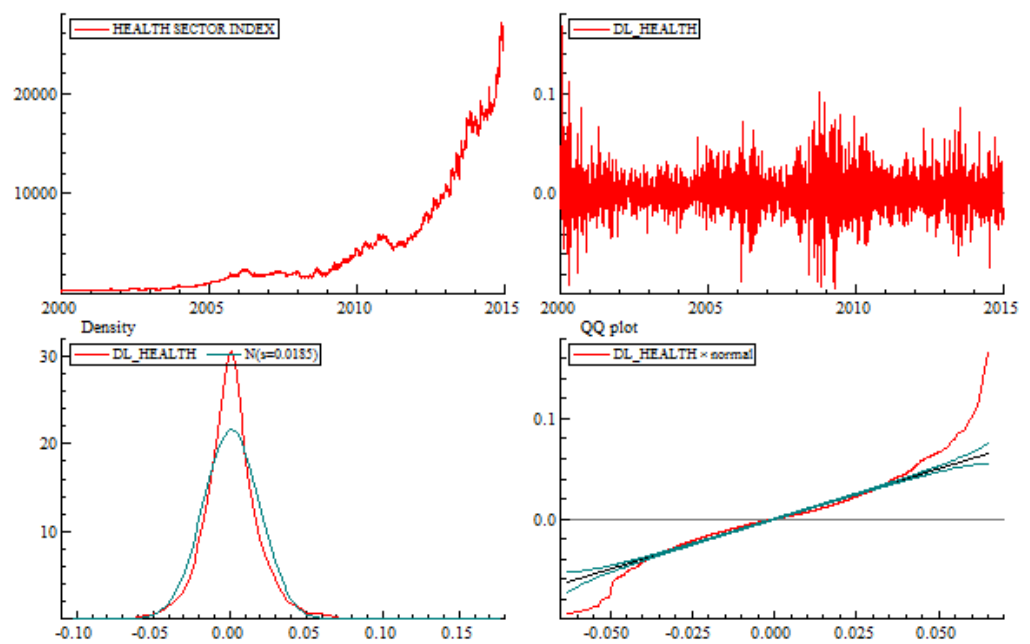

Figure A.6: Industrials Index in level, daily returns, daily returns density (versus normal) and QQ-plot against the normal distribution.

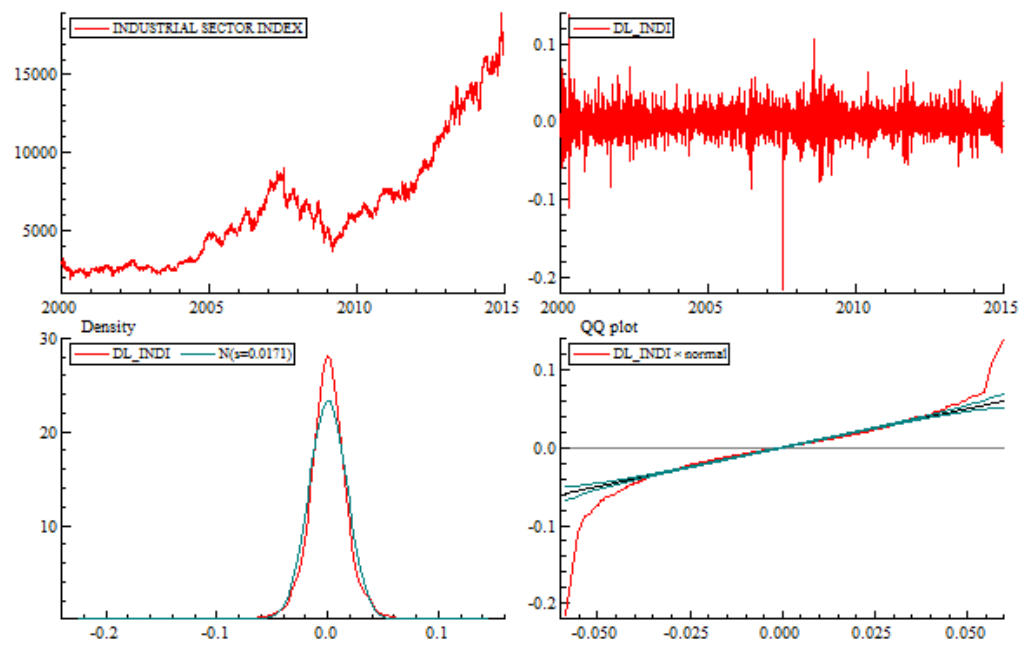


Figure A.7: Information Technology Index in level, daily returns, daily returns density (versus normal) and QQ-plot against the normal distribution.
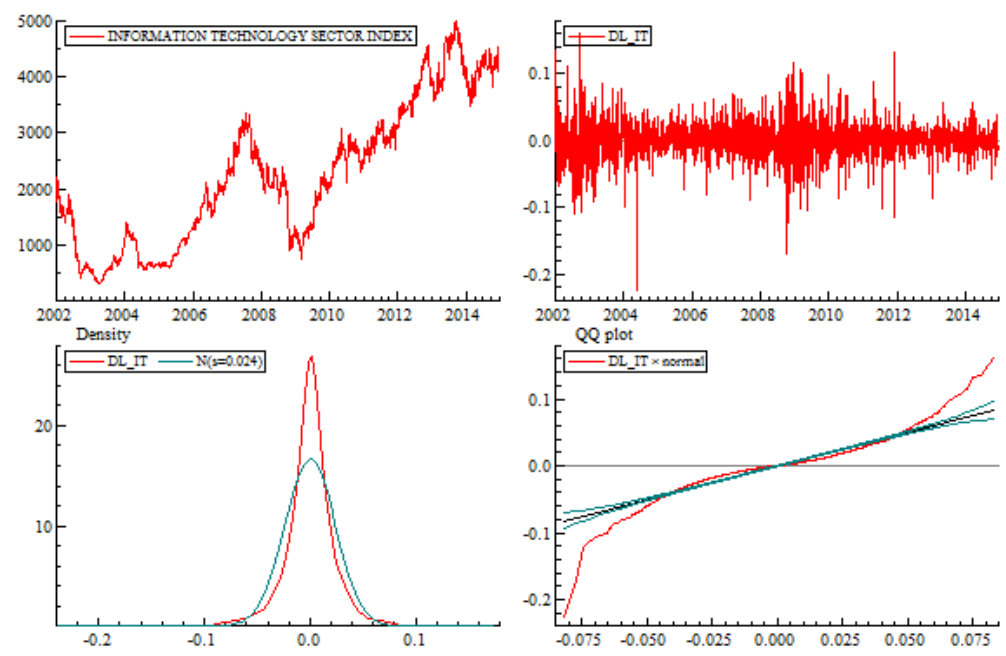

Figure A.8: Telecommunications Index in level, daily returns, daily returns density (versus normal) and QQ-plot against the normal distribution.
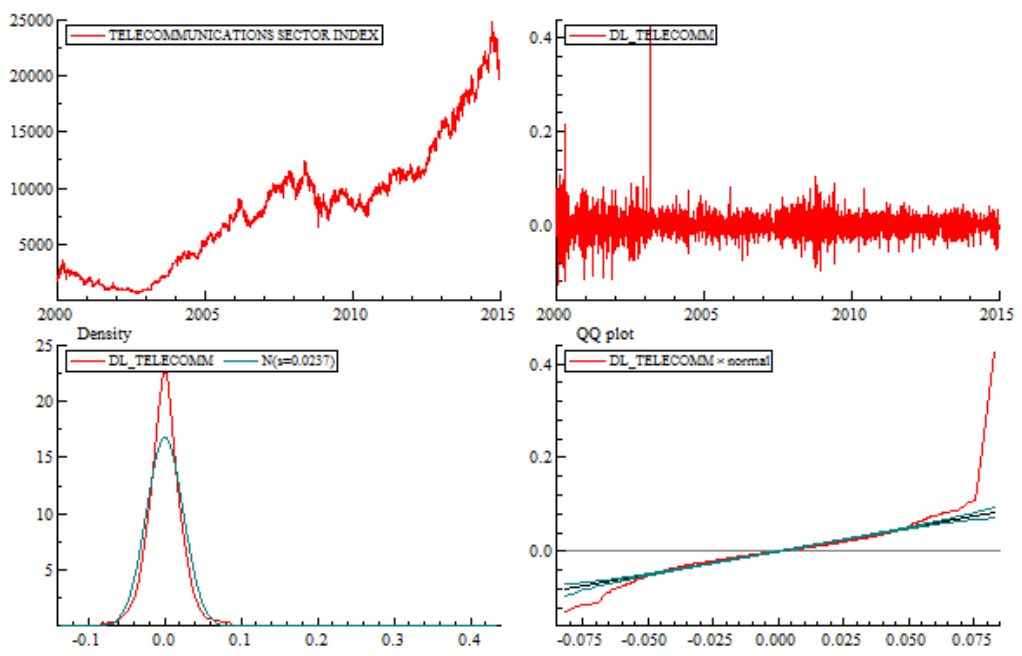
Table A.3: Health Index: VaR Results

\begin{tabular}{|c|c|c|c|c|c|c|}
\hline \multicolumn{7}{|c|}{ GARCH $(1,1)$} \\
\hline \multirow{2}{*}{ Confidence Level } & \multicolumn{3}{|c|}{ Short Position } & \multicolumn{3}{|c|}{ Long Position } \\
\hline & DQ & FR & ESF & DQ & $\mathrm{FR}$ & $\mathrm{ESF}$ \\
\hline $95 \%$ & 0.092881 & 0.93968 & 0.036625 & 0.36556 & 0.055556 & -0.032269 \\
\hline $97.5 \%$ & 0.92811 & 0.9746 & 0.046165 & 0.52768 & 0.022222 & -0.04014 \\
\hline $99 \%$ & 0.46164 & 0.99206 & 0.056758 & 0.19277 & 0.0063492 & -0.048049 \\
\hline \multicolumn{7}{|c|}{$\begin{array}{l}\text { IGARCH }(1,1) \\
\end{array}$} \\
\hline \multirow[t]{2}{*}{ Confidence Level } & \multicolumn{3}{|c|}{ Short Position } & \multicolumn{3}{|c|}{ Long Position } \\
\hline & DQ & FR & ESF & DQ & FR & ESF \\
\hline $95 \%$ & 0.36556 & 0.94444 & 0.037049 & 0.51808 & 0.053968 & -0.032571 \\
\hline $97.5 \%$ & 0.92811 & 0.9754 & 0.04642 & 0.24084 & 0.019841 & -0.040275 \\
\hline $99 \%$ & 0.30806 & 0.99286 & 0.056746 & 0.11284 & 0.0055556 & -0.049368 \\
\hline \multicolumn{7}{|c|}{ GJR-GARCH $(1,1)$} \\
\hline \multirow{2}{*}{ Confidence Level } & \multicolumn{3}{|c|}{ Short Position } & \multicolumn{3}{|c|}{ Long Position } \\
\hline & DQ & FR & ESF & DQ & FR & ESF \\
\hline $95 \%$ & 0.24469 & 0.94286 & 0.037271 & 0.51808 & 0.053968 & -0.032571 \\
\hline $97.5 \%$ & 0.78665 & 0.97381 & 0.045565 & 0.32098 & 0.020635 & -0.039915 \\
\hline $99 \%$ & 0.65053 & 0.99127 & 0.056371 & 0.19277 & 0.0063492 & -0.048049 \\
\hline \multicolumn{7}{|c|}{$\begin{array}{l}\text { EGARCH }(1,1) \\
\end{array}$} \\
\hline \multirow[t]{2}{*}{ Confidence Level } & \multicolumn{3}{|c|}{ Short Position } & \multicolumn{3}{|c|}{ Long Position } \\
\hline & DQ & FR & ESF & DQ & FR & ESF \\
\hline $95 \%$ & 0.796 & 0.95159 & 0.037734 & 0.51808 & 0.046032 & -0.031729 \\
\hline $97.5 \%$ & 0.24084 & 0.98016 & 0.045357 & 0.086489 & 0.01746 & -0.036985 \\
\hline $99 \%$ & 0.30806 & 0.99286 & 0.054569 & 0.11284 & 0.0055556 & -0.047508 \\
\hline \multicolumn{7}{|c|}{$\operatorname{APARCH}(1,1)$} \\
\hline \multirow[t]{2}{*}{ Confidence Level } & \multicolumn{3}{|c|}{ Short Position } & \multicolumn{3}{|c|}{ Long Position } \\
\hline & DQ & FR & ESF & DQ & FR & $\mathrm{ESF}$ \\
\hline $95 \%$ & 0.24469 & 0.94286 & 0.037314 & 0.51808 & 0.053968 & -0.032514 \\
\hline $97.5 \%$ & 0.92811 & 0.9746 & 0.046219 & 0.41679 & 0.021429 & -0.039905 \\
\hline $99 \%$ & 0.30806 & 0.99286 & 0.056746 & 0.19277 & 0.0063492 & -0.048049 \\
\hline \multicolumn{7}{|c|}{ FIGARCH $(1,1)$} \\
\hline \multirow[t]{2}{*}{ Confidence Level } & \multicolumn{3}{|c|}{ Short Position } & \multicolumn{3}{|c|}{ Long Position } \\
\hline & DQ & FR & ESF & DQ & FR & $\mathrm{ESF}$ \\
\hline $95 \%$ & 0.038623 & 0.9373 & 0.036446 & 0.36556 & 0.055556 & -0.032508 \\
\hline $97.5 \%$ & 0.92811 & 0.9746 & 0.046739 & 0.41679 & 0.021429 & -0.03874 \\
\hline $99 \%$ & 0.8651 & 0.99048 & 0.053816 & 0.30806 & 0.0071429 & -0.047775 \\
\hline \multicolumn{7}{|c|}{ FIAPARCH $(1,1)$} \\
\hline Confidence Level & & ort Positi & & & Long Positi & \\
\hline & DQ & FR & $\mathrm{ESF}$ & DQ & FR & $\mathrm{ESF}$ \\
\hline $95 \%$ & 0.038623 & 0.9373 & 0.036446 & 0.36556 & 0.055556 & -0.032453 \\
\hline $97.5 \%$ & 0.92811 & 0.9746 & 0.046739 & 0.41679 & 0.021429 & -0.03874 \\
\hline $99 \%$ & 0.8651 & 0.99048 & 0.053816 & 0.30806 & 0.0071429 & -0.047775 \\
\hline
\end{tabular}

DQ corresponds to the $p$-value of the Dynamic Quantile test. .

FR shows the failure rate as per Kupiec's (1995) test.

ESF shows the expected shortfall when the VaR is breached. 
Table A.4: Consumer Discretionary Index: VaR Results

\begin{tabular}{|c|c|c|c|c|c|c|}
\hline \multicolumn{7}{|c|}{$\operatorname{GARCH}(1,1)$} \\
\hline \multirow{2}{*}{ Confidence Level } & \multicolumn{3}{|c|}{ Short Position } & \multicolumn{3}{|c|}{ Long Position } \\
\hline & DQ & FR & $\mathrm{ESF}$ & DQ & FR & $\mathrm{ESF}$ \\
\hline $95 \%$ & 0.19615 & 0.94206 & 0.048077 & 0.24469 & 0.057143 & -0.045818 \\
\hline $97.5 \%$ & 0.92811 & 0.9746 & 0.060973 & 0.024099 & 0.034921 & -0.052416 \\
\hline $99 \%$ & 0.33571 & 0.9873 & 0.073954 & 0.00014822 & 0.020635 & -0.054186 \\
\hline \multicolumn{7}{|c|}{ IGARCH $(1,1)$} \\
\hline \multirow[t]{2}{*}{ Confidence Level } & \multicolumn{3}{|c|}{ Short Position } & \multicolumn{3}{|c|}{ Long Position } \\
\hline & DQ & FR & ESF & DQ & FR & ESF \\
\hline $95 \%$ & 0.36556 & 0.94444 & 0.048322 & 0.51808 & 0.053968 & -0.046544 \\
\hline $97.5 \%$ & 0.65191 & 0.97698 & 0.063483 & 0.037977 & 0.034127 & -0.052689 \\
\hline $99 \%$ & 0.4968 & 0.9881 & 0.073722 & 0.0077795 & 0.01746 & -0.054207 \\
\hline \multicolumn{7}{|c|}{ GJR-GARCH $(1,1)$} \\
\hline \multirow{2}{*}{ Confidence Level } & \multicolumn{3}{|c|}{ Short Position } & \multicolumn{3}{|c|}{ Long Position } \\
\hline & DQ & FR & ESF & DQ & FR & $\mathrm{ESF}$ \\
\hline $95 \%$ & 0.15506 & 0.94127 & 0.046904 & 0.12087 & 0.059524 & -0.046127 \\
\hline $97.5 \%$ & 0.52768 & 0.97222 & 0.059778 & 0.0088853 & 0.036508 & -0.051014 \\
\hline $99 \%$ & 0.4968 & 0.9881 & 0.073722 & 0.00044659 & 0.019841 & -0.054303 \\
\hline \multicolumn{7}{|c|}{ EGARCH $(1,1)$} \\
\hline \multirow[t]{2}{*}{ Confidence Level } & \multicolumn{3}{|c|}{ Short Position } & \multicolumn{3}{|c|}{ Long Position } \\
\hline & DQ & FR & ESF & DQ & FR & ESF \\
\hline $95 \%$ & 0.69818 & 0.94762 & 0.047632 & 0.69818 & 0.052381 & -0.045195 \\
\hline $97.5 \%$ & 0.65191 & 0.97302 & 0.055106 & 0.41679 & 0.028571 & -0.048737 \\
\hline $99 \%$ & 0.90983 & 0.98968 & 0.070367 & 0.12628 & 0.014286 & -0.054496 \\
\hline \multicolumn{7}{|c|}{ APARCH $(1,1)$} \\
\hline \multirow[t]{2}{*}{ Confidence Level } & \multicolumn{3}{|c|}{ Short Position } & \multicolumn{3}{|c|}{ Long Position } \\
\hline & DQ & FR & ESF & DQ & FR & ESF \\
\hline $95 \%$ & 0.15506 & 0.94127 & 0.046894 & 0.15506 & 0.05873 & -0.046183 \\
\hline $97.5 \%$ & 0.32098 & 0.97063 & 0.058895 & 0.0088853 & 0.036508 & -0.051014 \\
\hline $99 \%$ & 0.4968 & 0.9881 & 0.074776 & $4.56 \mathrm{E}-05$ & 0.021429 & -0.053322 \\
\hline \multicolumn{7}{|c|}{ FIGARCH $(1,1)$} \\
\hline \multirow[t]{2}{*}{ Confidence Level } & \multicolumn{3}{|c|}{ Short Position } & \multicolumn{3}{|c|}{ Long Position } \\
\hline & DQ & FR & ESF & DQ & FR & ESF \\
\hline $95 \%$ & 0.438 & 0.94524 & 0.04925 & 0.12087 & 0.059524 & -0.04665 \\
\hline $97.5 \%$ & 0.78665 & 0.97381 & 0.06249 & 0.0051598 & 0.037302 & -0.051636 \\
\hline $99 \%$ & 0.69182 & 0.98889 & 0.076894 & 0.0012476 & 0.019048 & -0.053983 \\
\hline \multicolumn{7}{|c|}{ FIAPARCH $(1,1)$} \\
\hline Confidence Level & & ort Posit & & & ng Positio & \\
\hline & DQ & FR & ESF & $\mathrm{DQ}$ & FR & ESF \\
\hline $95 \%$ & 0.36556 & 0.94444 & 0.048535 & 0.24469 & 0.057143 & -0.046817 \\
\hline $97.5 \%$ & 0.65191 & 0.97302 & 0.062878 & 0.0029077 & 0.038095 & -0.050489 \\
\hline $99 \%$ & 0.69182 & 0.98889 & 0.073592 & 0.01739 & 0.016667 & -0.056417 \\
\hline
\end{tabular}

DQ corresponds to the $p$-value of the Dynamic Quantile test. .

FR shows the failure rate as per Kupiec's (1995) test.

ESF shows the expected shortfall when the VaR is breached. 
Table A.5: Consumer Staples Index: VaR Results

\begin{tabular}{|c|c|c|c|c|c|c|}
\hline \multicolumn{7}{|c|}{$\operatorname{GARCH}(1,1)$} \\
\hline \multirow[t]{2}{*}{ Confidence Level } & \multicolumn{3}{|c|}{ Short Position } & \multicolumn{3}{|c|}{ Long Position } \\
\hline & DQ & FR & ESF & DQ & FR & ESF \\
\hline $95 \%$ & 0.24469 & 0.95714 & 0.03161 & 0.69818 & 0.05238 & -0.02770 \\
\hline $97.5 \%$ & 0.52768 & 0.97778 & 0.03738 & 0.32098 & 0.02064 & -0.03461 \\
\hline $99 \%$ & 0.19277 & 0.99365 & 0.05279 & 0.46164 & 0.00794 & -0.04074 \\
\hline \multicolumn{7}{|c|}{$\operatorname{IGARCH}(1,1)$} \\
\hline \multirow[t]{2}{*}{ Confidence Level } & \multicolumn{3}{|c|}{ Short Position } & \multicolumn{3}{|c|}{ Long Position } \\
\hline & DQ & FR & ESF & DQ & FR & ESF \\
\hline $95 \%$ & 0.15506 & 0.95873 & 0.03125 & 0.43800 & 0.05476 & -0.02709 \\
\hline $97.5 \%$ & 0.65191 & 0.97698 & 0.03708 & 0.24084 & 0.01984 & -0.03449 \\
\hline $99 \%$ & 0.65053 & 0.99127 & 0.04655 & 0.30806 & 0.00714 & -0.04036 \\
\hline \multicolumn{7}{|c|}{ GJR-GARCH $(1,1)$} \\
\hline \multirow[t]{2}{*}{ Confidence Level } & \multicolumn{3}{|c|}{ Short Position } & \multicolumn{3}{|c|}{ Long Position } \\
\hline & DQ & FR & ESF & DQ & FR & ESF \\
\hline $95 \%$ & 0.15506 & 0.95873 & 0.03187 & 1.00000 & 0.05000 & -0.02772 \\
\hline $97.5 \%$ & 0.41679 & 0.97857 & 0.03721 & 0.32098 & 0.02064 & -0.03483 \\
\hline $99 \%$ & 0.30806 & 0.99286 & 0.05053 & 0.19277 & 0.00635 & -0.04118 \\
\hline \multicolumn{7}{|c|}{$\operatorname{EGARCH}(1,1)$} \\
\hline \multirow[t]{2}{*}{ Confidence Level } & \multicolumn{3}{|c|}{ Short Position } & \multicolumn{3}{|c|}{ Long Position } \\
\hline & DQ & FR & ESF & DQ & FR & ESF \\
\hline $95 \%$ & 0.79600 & 0.95159 & 0.02851 & 0.15506 & 0.05873 & -0.02621 \\
\hline $97.5 \%$ & 0.92811 & 0.97540 & 0.03322 & 0.92811 & 0.02540 & -0.03127 \\
\hline $99 \%$ & 0.49680 & 0.98810 & 0.03960 & 0.30806 & 0.00714 & -0.03788 \\
\hline \multicolumn{7}{|c|}{ APARCH $(1,1)$} \\
\hline \multirow[t]{2}{*}{ Confidence Level } & \multicolumn{3}{|c|}{ Short Position } & \multicolumn{3}{|c|}{ Long Position } \\
\hline & $\mathrm{DQ}$ & FR & ESF & DQ & FR & ESF \\
\hline $95 \%$ & 0.24469 & 0.95714 & 0.03135 & 0.51808 & 0.05397 & -0.02729 \\
\hline $97.5 \%$ & 0.41679 & 0.97857 & 0.03760 & 0.32098 & 0.02064 & -0.03450 \\
\hline $99 \%$ & 0.65053 & 0.99127 & 0.04569 & 0.65053 & 0.00873 & -0.04162 \\
\hline \multicolumn{7}{|c|}{ FIGARCH $(1,1)$} \\
\hline \multirow[t]{2}{*}{ Confidence Level } & \multicolumn{3}{|c|}{ Short Position } & \multicolumn{3}{|c|}{ Long Position } \\
\hline & $\mathrm{DQ}$ & FR & ESF & DQ & FR & ESF \\
\hline $95 \%$ & 0.36556 & 0.95556 & 0.03149 & 0.30109 & 0.05635 & -0.02700 \\
\hline $97.5 \%$ & 0.52768 & 0.97778 & 0.03697 & 0.65191 & 0.02302 & -0.03389 \\
\hline $99 \%$ & 0.86510 & 0.99048 & 0.04573 & 0.65053 & 0.00873 & -0.03955 \\
\hline \multicolumn{7}{|c|}{ FIAPARCH $(1,1)$} \\
\hline Confidence Level & & ort Posit & & & nng Positi & \\
\hline & DQ & FR & ESF & $\mathrm{DQ}$ & FR & ESF \\
\hline $95 \%$ & 0.36556 & 0.95556 & 0.03121 & 0.60513 & 0.05318 & -0.02730 \\
\hline $97.5 \%$ & 0.41679 & 0.97857 & 0.03721 & 0.41679 & 0.02143 & -0.03440 \\
\hline $99 \%$ & 0.65053 & 0.99127 & 0.04658 & 0.86510 & 0.00952 & -0.04089 \\
\hline
\end{tabular}

DQ corresponds to the $p$-value of the Dynamic Quantile test. .

FR shows the failure rate as per Kupiec's (1995) test.

ESF shows the expected shortfall when the VaR is breached. 
Table A.6: Financials Index: VaR Results

\begin{tabular}{|c|c|c|c|c|c|c|}
\hline \multicolumn{7}{|c|}{$\operatorname{GARCH}(1,1)$} \\
\hline \multirow[t]{2}{*}{ Confidence Level } & \multicolumn{3}{|c|}{ Short Position } & \multicolumn{3}{|c|}{ Long Position } \\
\hline & DQ & FR & ESF & DQ & FR & ESF \\
\hline $95 \%$ & 0.027989 & 0.96349 & 0.028245 & 0.052511 & 0.038095 & -0.025936 \\
\hline $97.5 \%$ & 0.014851 & 0.98571 & 0.033951 & 0.086489 & 0.01746 & -0.030283 \\
\hline $99 \%$ & 0.03141 & 0.99603 & 0.038414 & 0.03141 & 0.0039683 & -0.039195 \\
\hline \multicolumn{7}{|c|}{ IGARCH $(1,1)$} \\
\hline \multirow[t]{2}{*}{ Confidence Level } & \multicolumn{3}{|c|}{ Short Position } & \multicolumn{3}{|c|}{ Long Position } \\
\hline & DQ & FR & ESF & DQ & $\mathrm{FR}$ & ESF \\
\hline $95 \%$ & 0.019981 & 0.96429 & 0.027576 & 0.092881 & 0.039683 & 0.081763 \\
\hline $97.5 \%$ & 0.0051598 & 0.9873 & 0.032196 & 0.086489 & 0.01746 & 0.070142 \\
\hline $99 \%$ & 0.014893 & 0.99683 & 0.0398 & 0.014893 & 0.0031746 & 0.0044758 \\
\hline \multicolumn{7}{|c|}{ GJR-GARCH $(1,1)$} \\
\hline \multirow[t]{2}{*}{ Confidence Level } & \multicolumn{3}{|c|}{ Short Position } & \multicolumn{3}{|c|}{ Long Position } \\
\hline & DQ & FR & $\mathrm{ESF}$ & DQ & FR & $\mathrm{ESF}$ \\
\hline $95 \%$ & 0.019981 & 0.96429 & 0.028374 & 0.027989 & 0.036508 & -0.026097 \\
\hline $97.5 \%$ & 0.037977 & 0.98413 & 0.03325 & 0.037977 & 0.015873 & -0.030627 \\
\hline $99 \%$ & 0.014893 & 0.99683 & 0.0398 & 0.03141 & 0.0039683 & -0.039195 \\
\hline \multicolumn{7}{|c|}{ EGARCH $(1,1)$} \\
\hline \multirow[t]{2}{*}{ Confidence Level } & \multicolumn{3}{|c|}{ Short Position } & \multicolumn{3}{|c|}{ Long Position } \\
\hline & DQ & FR & ESF & DQ & FR & ESF \\
\hline $95 \%$ & 0.438 & 0.95476 & 0.024874 & 0.69818 & 0.047619 & -0.022242 \\
\hline $97.5 \%$ & 0.058137 & 0.98333 & 0.028676 & 0.41679 & 0.028571 & -0.025629 \\
\hline $99 \%$ & 0.03141 & 0.99603 & 0.040244 & 0.30806 & 0.0071429 & -0.028153 \\
\hline \multicolumn{7}{|c|}{$\operatorname{APARCH}(1,1)$} \\
\hline \multirow[t]{2}{*}{ Confidence Level } & \multicolumn{3}{|c|}{ Short Position } & \multicolumn{3}{|c|}{ Long Position } \\
\hline & DQ & FR & ESF & $\mathrm{DQ}$ & FR & $\mathrm{ESF}$ \\
\hline $95 \%$ & 0.014051 & 0.96508 & 0.028112 & 0.052511 & 0.038095 & -0.025304 \\
\hline $97.5 \%$ & 0.0088853 & 0.98651 & 0.032951 & 0.086489 & 0.01746 & -0.030043 \\
\hline $99 \%$ & 0.0065654 & 0.99762 & 0.042046 & 0.061664 & 0.0047619 & -0.03691 \\
\hline \multicolumn{7}{|c|}{ FIGARCH $(1,1)$} \\
\hline \multirow[t]{2}{*}{ Confidence Level } & \multicolumn{3}{|c|}{ Short Position } & \multicolumn{3}{|c|}{ Long Position } \\
\hline & DQ & FR & ESF & DQ & FR & ESF \\
\hline $95 \%$ & 0.19615 & 0.95794 & 0.026929 & 0.438 & 0.045238 & -0.024529 \\
\hline $97.5 \%$ & 0.037977 & 0.98413 & 0.033129 & 0.52768 & 0.022222 & -0.027979 \\
\hline $99 \%$ & 0.061664 & 0.99524 & 0.036422 & 0.11284 & 0.0055556 & -0.036313 \\
\hline \multicolumn{7}{|c|}{ FIAPARCH $(1,1)$} \\
\hline Confidence Level & & rt Positi & & & ung Positic & \\
\hline & DQ & FR & $\mathrm{ESF}$ & DQ & FR & $\mathrm{ESF}$ \\
\hline $95 \%$ & 0.092881 & 0.96032 & 0.027278 & 0.052511 & 0.038095 & -0.025618 \\
\hline $97.5 \%$ & 0.0088853 & 0.98651 & 0.033152 & 0.058137 & 0.016667 & -0.030469 \\
\hline $99 \%$ & 0.0065654 & 0.99762 & 0.042046 & 0.11284 & 0.0055556 & -0.036313 \\
\hline
\end{tabular}

DQ corresponds to the $p$-value of the Dynamic Quantile test. .

FR shows the failure rate as per Kupiec's (1995) test.

ESF shows the expected shortfall when the VaR is breached. 
Table A.7: Industrials Index: VaR Results

\begin{tabular}{|c|c|c|c|c|c|c|}
\hline \multicolumn{7}{|c|}{ GARCH $(1,1)$} \\
\hline \multirow{2}{*}{ Confidence Level } & \multicolumn{3}{|c|}{ Short Position } & \multicolumn{3}{|c|}{ Long Position } \\
\hline & DQ & FR & $\mathrm{ESF}$ & DQ & FR & $\mathrm{ESF}$ \\
\hline $95 \%$ & 0.24469 & 0.95714 & 0.035368 & 0.052511 & 0.038095 & -0.033205 \\
\hline $97.5 \%$ & 0.92811 & 0.9754 & 0.040342 & 0.24084 & 0.019841 & -0.03911 \\
\hline $99 \%$ & 0.19277 & 0.99365 & 0.048485 & 0.65053 & 0.0087302 & -0.046934 \\
\hline \multicolumn{7}{|c|}{ IGARCH $(1,1)$} \\
\hline \multirow[t]{2}{*}{ Confidence Level } & \multicolumn{3}{|c|}{ Short Position } & \multicolumn{3}{|c|}{ Long Position } \\
\hline & DQ & FR & ESF & DQ & FR & ESF \\
\hline $95 \%$ & 0.19615 & 0.95794 & 0.034348 & 0.019981 & 0.035714 & -0.032759 \\
\hline $97.5 \%$ & 0.52768 & 0.97778 & 0.037866 & 0.12509 & 0.018254 & -0.039663 \\
\hline $99 \%$ & 0.061664 & 0.99524 & 0.049341 & 0.30806 & 0.0071429 & -0.045316 \\
\hline \multicolumn{7}{|c|}{ GJR-GARCH $(1,1)$} \\
\hline \multirow[t]{2}{*}{ Confidence Level } & \multicolumn{3}{|c|}{ Short Position } & \multicolumn{3}{|c|}{ Long Position } \\
\hline & DQ & FR & ESF & DQ & FR & ESF \\
\hline $95 \%$ & 0.438 & 0.95476 & 0.034745 & 0.092881 & 0.039683 & -0.033684 \\
\hline $97.5 \%$ & 0.92811 & 0.9754 & 0.039191 & 0.24084 & 0.019841 & -0.039454 \\
\hline $99 \%$ & 0.30806 & 0.99286 & 0.048624 & 0.8651 & 0.0095238 & -0.046511 \\
\hline \multicolumn{7}{|c|}{ EGARCH $(1,1)$} \\
\hline \multirow[t]{2}{*}{ Confidence Level } & \multicolumn{3}{|c|}{ Short Position } & \multicolumn{3}{|c|}{ Long Position } \\
\hline & DQ & FR & ESF & DQ & FR & ESF \\
\hline $95 \%$ & 0.36556 & 0.95556 & 0.03256 & 0.69818 & 0.047619 & -0.02906 \\
\hline $97.5 \%$ & 0.92811 & 0.9754 & 0.03581 & 0.65191 & 0.023016 & -0.036116 \\
\hline $99 \%$ & 0.11284 & 0.99444 & 0.045925 & 0.30806 & 0.0071429 & -0.043003 \\
\hline \multicolumn{7}{|c|}{$\operatorname{APARCH}(1,1)$} \\
\hline \multirow[t]{2}{*}{ Confidence Level } & \multicolumn{3}{|c|}{ Short Position } & \multicolumn{3}{|c|}{ Long Position } \\
\hline & DQ & FR & ESF & DQ & FR & ESF \\
\hline $95 \%$ & 0.36556 & 0.95556 & 0.035293 & 0.070349 & 0.038889 & -0.033895 \\
\hline $97.5 \%$ & 0.78665 & 0.97381 & 0.039791 & 0.32098 & 0.020635 & -0.039819 \\
\hline $99 \%$ & 0.30806 & 0.99286 & 0.048624 & 0.8651 & 0.0095238 & -0.046133 \\
\hline \multicolumn{7}{|c|}{$\begin{array}{l}\text { FIGARCH }(1,1) \\
\end{array}$} \\
\hline \multirow[t]{2}{*}{ Confidence Level } & \multicolumn{3}{|c|}{ Short Position } & \multicolumn{3}{|c|}{ Long Position } \\
\hline & DQ & FR & ESF & DQ & FR & ESF \\
\hline $95 \%$ & 0.796 & 0.94841 & 0.033814 & 0.24469 & 0.042857 & -0.031985 \\
\hline $97.5 \%$ & 0.65191 & 0.97302 & 0.039509 & 0.32098 & 0.020635 & -0.039022 \\
\hline $99 \%$ & 0.65053 & 0.99127 & 0.046747 & 0.90983 & 0.010317 & -0.045025 \\
\hline \multicolumn{7}{|c|}{ FIAPARCH $(1,1)$} \\
\hline Confidence Level & & ort Positi & & & ung Positic & \\
\hline & DQ & FR & ESF & DQ & FR & ESF \\
\hline $95 \%$ & 0.36556 & 0.95556 & 0.035657 & 0.438 & 0.045238 & -0.03267 \\
\hline $97.5 \%$ & 0.41679 & 0.97143 & 0.039538 & 0.52768 & 0.022222 & -0.038598 \\
\hline $99 \%$ & 0.46164 & 0.99206 & 0.046304 & 0.65053 & 0.0087302 & -0.046675 \\
\hline
\end{tabular}

DQ corresponds to the $p$-value of the Dynamic Quantile test. .

FR shows the failure rate as per Kupiec's (1995) test.

ESF shows the expected shortfall when the VaR is breached. 
Table A.8: Energy Index: VaR Results

\begin{tabular}{|c|c|c|c|c|c|c|}
\hline \multicolumn{7}{|c|}{$\overline{\operatorname{GARCH}(1,1)}$} \\
\hline \multirow[t]{2}{*}{ Confidence Level } & \multicolumn{3}{|c|}{ Short Position } & \multicolumn{3}{|c|}{ Long Position } \\
\hline & DQ & FR & ESF & DQ & FR & ESF \\
\hline $95 \%$ & 0.00010539 & 0.97381 & 0.037587 & 0.019981 & 0.035714 & 1.2482 \\
\hline $97.5 \%$ & 0.0051598 & 0.9873 & 0.045985 & 0.037977 & 0.015873 & 1.215 \\
\hline $99 \%$ & 0.11284 & 0.99444 & 0.05882 & 0.11284 & 0.0055556 & 1.2381 \\
\hline \multicolumn{7}{|c|}{$\operatorname{IGARCH}(1,1)$} \\
\hline \multirow[t]{2}{*}{ Confidence Level } & \multicolumn{3}{|c|}{ Short Position } & \multicolumn{3}{|c|}{ Long Position } \\
\hline & DQ & FR & $\mathrm{ESF}$ & DQ & FR & ESF \\
\hline $95 \%$ & 0.052511 & 0.9619 & 0.034021 & 0.12087 & 0.040476 & -0.033735 \\
\hline $97.5 \%$ & 0.0088853 & 0.98651 & 0.043932 & 0.24084 & 0.019841 & -0.037705 \\
\hline $99 \%$ & 0.46164 & 0.99206 & 0.050869 & 0.46164 & 0.0079365 & -0.042302 \\
\hline \multicolumn{7}{|c|}{ GJR-GARCH(1, 1) } \\
\hline \multirow[t]{2}{*}{ Confidence Level } & \multicolumn{3}{|c|}{ Short Position } & \multicolumn{3}{|c|}{ Long Position } \\
\hline & DQ & FR & ESF & DQ & FR & ESF \\
\hline $95 \%$ & $3.53 \mathrm{E}-05$ & 0.9754 & 0.03792 & 0.0066379 & 0.033333 & -0.036088 \\
\hline $97.5 \%$ & 0.0051598 & 0.9873 & 0.045985 & 0.024099 & 0.015079 & -0.041693 \\
\hline $99 \%$ & 0.11284 & 0.99444 & 0.05882 & 0.11284 & 0.0055556 & -0.05029 \\
\hline \multicolumn{7}{|c|}{ EGARCH $(1,1)$} \\
\hline \multirow[t]{2}{*}{ Confidence Level } & \multicolumn{3}{|c|}{ Short Position } & \multicolumn{3}{|c|}{ Long Position } \\
\hline & DQ & FR & ESF & DQ & FR & ESF \\
\hline $95 \%$ & 0.092881 & 0.96032 & 0.030997 & 0.51808 & 0.046032 & -0.030946 \\
\hline $97.5 \%$ & 0.17595 & 0.98095 & 0.036554 & 0.65191 & 0.023016 & -0.032901 \\
\hline $99 \%$ & 0.46164 & 0.99206 & 0.045867 & 0.8651 & 0.0095238 & -0.040728 \\
\hline \multicolumn{7}{|c|}{$\operatorname{APARCH}(1,1)$} \\
\hline \multirow[t]{2}{*}{ Confidence Level } & \multicolumn{3}{|c|}{ Short Position } & \multicolumn{3}{|c|}{ Long Position } \\
\hline & DQ & $\mathrm{FR}$ & ESF & DQ & FR & ESF \\
\hline $95 \%$ & $6.15 \mathrm{E}-05$ & 0.9746 & 0.037407 & 0.0097316 & 0.034127 & -0.035728 \\
\hline $97.5 \%$ & 0.0029077 & 0.9881 & 0.046292 & 0.037977 & 0.015873 & -0.040994 \\
\hline $99 \%$ & 0.061664 & 0.99524 & 0.059858 & 0.11284 & 0.0055556 & -0.05029 \\
\hline \multicolumn{7}{|c|}{ FIGARCH $(1,1)$} \\
\hline \multirow[t]{2}{*}{ Confidence Level } & \multicolumn{3}{|c|}{ Short Position } & \multicolumn{3}{|c|}{ Long Position } \\
\hline & DQ & FR & ESF & DQ & FR & ESF \\
\hline $95 \%$ & 0.027989 & 0.96349 & 0.03421 & 0.36556 & 0.044444 & -0.032986 \\
\hline $97.5 \%$ & 0.058137 & 0.98333 & 0.041156 & 0.32098 & 0.020635 & -0.037259 \\
\hline $99 \%$ & 0.8651 & 0.99048 & 0.048721 & 0.8651 & 0.0095238 & -0.041892 \\
\hline \multicolumn{7}{|c|}{ FIAPARCH $(1,1)$} \\
\hline Confidence Level & & rt Positio & & & ong Positiol & \\
\hline & $\mathrm{DQ}$ & $\mathrm{FR}$ & ESF & DQ & FR & $\mathrm{ESF}$ \\
\hline $95 \%$ & 0.019981 & 0.96429 & 0.034338 & 0.092881 & 0.039683 & -0.034207 \\
\hline $97.5 \%$ & 0.024099 & 0.98492 & 0.043677 & 0.41679 & 0.021429 & -0.037903 \\
\hline $99 \%$ & 0.19277 & 0.99365 & 0.055134 & 0.30806 & 0.0071429 & -0.044071 \\
\hline
\end{tabular}

DQ corresponds to the $p$-value of the Dynamic Quantile test. .

FR shows the failure rate as per Kupiec's (1995) test.

ESF shows the expected shortfall when the VaR is breached. 
Table A.9: Information Technology Index: VaR Results

\begin{tabular}{|c|c|c|c|c|c|c|}
\hline \multicolumn{7}{|c|}{$\overline{\operatorname{GARCH}(1,1)}$} \\
\hline \multirow[t]{2}{*}{ Confidence Level } & \multicolumn{3}{|c|}{ Short Position } & \multicolumn{3}{|c|}{ Long Position } \\
\hline & DQ & FR & $\mathrm{ESF}$ & DQ & FR & $\mathrm{ESF}$ \\
\hline $95 \%$ & 0.12087 & 0.95952 & 0.043367 & 0.070349 & 0.038889 & -0.041524 \\
\hline $97.5 \%$ & 0.037977 & 0.98413 & 0.05937 & 0.014851 & 0.014286 & -0.060011 \\
\hline $99 \%$ & 0.19277 & 0.99365 & 0.071259 & 0.65053 & 0.0087302 & -0.073176 \\
\hline \multicolumn{7}{|c|}{ IGARCH $(1,1)$} \\
\hline \multirow[t]{2}{*}{ Confidence Level } & \multicolumn{3}{|c|}{ Short Position } & \multicolumn{3}{|c|}{ Long Position } \\
\hline & DQ & $\mathrm{FR}$ & $\mathrm{ESF}$ & DQ & $\mathrm{FR}$ & ESF \\
\hline $95 \%$ & 0.12087 & 0.95952 & 0.043367 & 0.070349 & 0.038889 & -0.041524 \\
\hline $97.5 \%$ & 0.024099 & 0.98492 & 0.058946 & 0.014851 & 0.014286 & -0.060011 \\
\hline $99 \%$ & 0.19277 & 0.99365 & 0.071259 & 0.8651 & 0.0095238 & -0.071281 \\
\hline \multicolumn{7}{|c|}{ "GJR-GARCH(1, 1) } \\
\hline \multirow[t]{2}{*}{ Confidence Level } & \multicolumn{3}{|c|}{ Short Position } & \multicolumn{3}{|c|}{ Long Position } \\
\hline & $\mathrm{DQ}$ & FR & $\mathrm{ESF}$ & DQ & FR & $\mathrm{ESF}$ \\
\hline $95 \%$ & 0.12087 & 0.95952 & 0.043367 & 0.092881 & 0.039683 & -0.041339 \\
\hline $97.5 \%$ & 0.024099 & 0.98492 & 0.058946 & 0.014851 & 0.014286 & -0.060011 \\
\hline $99 \%$ & 0.19277 & 0.99365 & 0.071259 & 0.65053 & 0.0087302 & -0.073176 \\
\hline \multicolumn{7}{|c|}{$\overline{\text { EGARCH}(1,1)}$} \\
\hline \multirow[t]{2}{*}{ Confidence Level } & \multicolumn{3}{|c|}{ Short Position } & \multicolumn{3}{|c|}{ Long Position } \\
\hline & $\mathrm{DQ}$ & FR & $\mathrm{ESF}$ & DQ & FR & ESF \\
\hline $95 \%$ & 0.027989 & 0.96349 & 0.042717 & 0.00048293 & 0.028571 & -0.044422 \\
\hline $97.5 \%$ & 0.00043374 & 0.99048 & 0.054164 & 0.0015898 & 0.011111 & -0.066348 \\
\hline $99 \%$ & 0.00036036 & & & 0.061664 & 0.0047619 & -0.082862 \\
\hline \multicolumn{7}{|c|}{$\overline{\mathrm{APARCH}}(\mathbf{1}, \mathbf{1})$} \\
\hline \multirow[t]{2}{*}{ Confidence Level } & \multicolumn{3}{|c|}{ Short Position } & \multicolumn{3}{|c|}{ Long Position } \\
\hline & DQ & FR & $\mathrm{ESF}$ & DQ & FR & ESF \\
\hline $95 \%$ & 0.60513 & 0.95317 & 0.040849 & 0.69818 & 0.047619 & -0.038899 \\
\hline $97.5 \%$ & 0.058137 & 0.98333 & 0.056631 & 0.014851 & 0.014286 & -0.060412 \\
\hline $99 \%$ & 0.11284 & 0.99444 & 0.073474 & 0.46164 & 0.0079365 & -0.075037 \\
\hline \multicolumn{7}{|c|}{ FIGARCH(1, 1) } \\
\hline \multirow[t]{2}{*}{ Confidence Level } & \multicolumn{3}{|c|}{ Short Position } & \multicolumn{3}{|c|}{ Long Position } \\
\hline & $\mathrm{DQ}$ & FR & $\mathrm{ESF}$ & $\mathrm{DQ}$ & FR & ESF \\
\hline $95 \%$ & 0.30109 & 0.95635 & 0.041742 & 0.24469 & 0.042857 & -0.039598 \\
\hline $97.5 \%$ & 0.12509 & 0.98175 & 0.055187 & 0.058137 & 0.016667 & -0.05679 \\
\hline $99 \%$ & 0.061664 & 0.99524 & 0.05648 & 0.90983 & 0.010317 & -0.068202 \\
\hline \multicolumn{7}{|c|}{ "FIAPARCH(1, 1) } \\
\hline Confidence Level & Sho & rt Positio & & & ng Positiol & \\
\hline & DQ & FR & $\mathrm{ESF}$ & $\mathrm{DQ}$ & FR & $\mathrm{ESF}$ \\
\hline $95 \%$ & 0.69818 & 0.95238 & 0.040687 & 0.30109 & 0.043651 & -0.039524 \\
\hline $97.5 \%$ & 0.086489 & 0.98254 & 0.056383 & 0.058137 & 0.016667 & -0.056709 \\
\hline $99 \%$ & 0.061664 & 0.99524 & 0.05648 & 0.90983 & 0.010317 & -0.068202 \\
\hline
\end{tabular}

DQ corresponds to the $p$-value of the Dynamic Quantile test. .

FR shows the failure rate as per Kupiec's (1995) test.

ESF shows the expected shortfall when the VaR is breached. 
Table A.10: Telecommunications Index: VaR Results

\begin{tabular}{|c|c|c|c|c|c|c|}
\hline \multicolumn{7}{|c|}{$\operatorname{GARCH}(1,1)$} \\
\hline \multirow[t]{2}{*}{ Confidence Level } & \multicolumn{3}{|c|}{ Short Position } & \multicolumn{3}{|c|}{ Long Position } \\
\hline & DQ & FR & ESF & DQ & FR & ESF \\
\hline $95 \%$ & 0.0012313 & 0.96984 & 0.0373 & 0.30109 & 0.043651 & -0.034994 \\
\hline $97.5 \%$ & 0.014851 & 0.98571 & 0.044663 & 0.058137 & 0.016667 & -0.044004 \\
\hline $99 \%$ & 0.03141 & 0.99603 & 0.058698 & 0.46164 & 0.0079365 & -0.049656 \\
\hline \multicolumn{7}{|c|}{$\operatorname{IGARCH}(1,1)$} \\
\hline \multirow[t]{2}{*}{ Confidence Level } & \multicolumn{3}{|c|}{ Short Position } & \multicolumn{3}{|c|}{ Long Position } \\
\hline & DQ & FR & $\mathrm{ESF}$ & DQ & FR & $\mathrm{ESF}$ \\
\hline $95 \%$ & 0.002949 & 0.96825 & 0.036205 & 0.36556 & 0.044444 & -0.034614 \\
\hline $97.5 \%$ & 0.024099 & 0.98492 & 0.043359 & 0.014851 & 0.014286 & -0.044267 \\
\hline $99 \%$ & 0.014893 & 0.99683 & 0.058702 & 0.30806 & 0.0071429 & -0.049546 \\
\hline \multicolumn{7}{|c|}{ GJR-GARCH $(1,1)$} \\
\hline \multirow[t]{2}{*}{ Confidence Level } & \multicolumn{3}{|c|}{ Short Position } & \multicolumn{3}{|c|}{ Long Position } \\
\hline & DQ & FR & $\mathrm{ESF}$ & DQ & $\mathrm{FR}$ & $\mathrm{ESF}$ \\
\hline $95 \%$ & 0.0019204 & 0.96905 & 0.037522 & 0.092881 & 0.039683 & -0.036147 \\
\hline $97.5 \%$ & 0.0088853 & 0.98651 & 0.045984 & 0.12509 & 0.018254 & -0.042923 \\
\hline $99 \%$ & 0.03141 & 0.99603 & 0.054935 & 0.8651 & 0.0095238 & -0.049204 \\
\hline \multicolumn{7}{|c|}{ EGARCH $(1,1)$} \\
\hline \multirow[t]{2}{*}{ Confidence Level } & \multicolumn{3}{|c|}{ Short Position } & \multicolumn{3}{|c|}{ Long Position } \\
\hline & DQ & FR & ESF & DQ & FR & ESF \\
\hline $95 \%$ & 0.052511 & 0.9619 & 0.033619 & 0.51808 & 0.046032 & -0.033323 \\
\hline $97.5 \%$ & 0.24084 & 0.98016 & 0.037433 & 0.41679 & 0.021429 & -0.038632 \\
\hline $99 \%$ & 0.061664 & 0.99524 & 0.052056 & 0.30806 & 0.0071429 & -0.044283 \\
\hline \multicolumn{7}{|c|}{ APARCH $(1,1)$} \\
\hline \multirow[t]{2}{*}{ Confidence Level } & \multicolumn{3}{|c|}{ Short Position } & \multicolumn{3}{|c|}{ Long Position } \\
\hline & DQ & FR & $\mathrm{ESF}$ & DQ & FR & ESF \\
\hline $95 \%$ & 0.002949 & 0.96825 & 0.036188 & 0.12087 & 0.040476 & -0.035344 \\
\hline $97.5 \%$ & 0.024099 & 0.98492 & 0.043585 & 0.17595 & 0.019048 & -0.042135 \\
\hline $99 \%$ & 0.03141 & 0.99603 & 0.054935 & 0.65053 & 0.0087302 & -0.048731 \\
\hline \multicolumn{7}{|c|}{$\operatorname{FIGARCH}(1,1)$} \\
\hline \multirow[t]{2}{*}{ Confidence Level } & \multicolumn{3}{|c|}{ Short Position } & \multicolumn{3}{|c|}{ Long Position } \\
\hline & DQ & FR & ESF & DQ & FR & ESF \\
\hline $95 \%$ & 0.019981 & 0.96429 & 0.035711 & 0.438 & 0.045238 & -0.034377 \\
\hline $97.5 \%$ & 0.12509 & 0.98175 & 0.041415 & 0.12509 & 0.018254 & -0.041771 \\
\hline $99 \%$ & 0.03141 & 0.99603 & 0.058698 & 0.46164 & 0.0079365 & -0.048539 \\
\hline \multicolumn{7}{|c|}{ FIAPARCH $(1,1)$} \\
\hline Confidence Level & & rt Positi & & & ung Positic & \\
\hline & DQ & FR & ESF & DQ & FR & ESF \\
\hline $95 \%$ & 0.0066379 & 0.96667 & 0.035949 & 0.438 & 0.045238 & -0.034993 \\
\hline $97.5 \%$ & 0.014851 & 0.98571 & 0.044457 & 0.058137 & 0.016667 & -0.042552 \\
\hline $99 \%$ & 0.11284 & 0.99444 & 0.054703 & 0.65053 & 0.0087302 & -0.048731 \\
\hline
\end{tabular}

DQ corresponds to the $p$-value of the Dynamic Quantile test. .

FR shows the failure rate as per Kupiec's (1995) test.

ESF shows the expected shortfall when the VaR is breached. 
Table A.11: Health Index: VaR Results

\begin{tabular}{|c|c|c|c|c|c|c|}
\hline \multicolumn{7}{|c|}{ GARCH $(1,1)$} \\
\hline \multirow{2}{*}{ Confidence Level } & \multicolumn{3}{|c|}{ Short Position } & \multicolumn{3}{|c|}{ Long Position } \\
\hline & DQ & FR & ESF & DQ & $\mathrm{FR}$ & $\mathrm{ESF}$ \\
\hline $95 \%$ & 0.092881 & 0.93968 & 0.036625 & 0.36556 & 0.055556 & -0.032269 \\
\hline $97.5 \%$ & 0.92811 & 0.9746 & 0.046165 & 0.52768 & 0.022222 & -0.04014 \\
\hline $99 \%$ & 0.46164 & 0.99206 & 0.056758 & 0.19277 & 0.0063492 & -0.048049 \\
\hline \multicolumn{7}{|c|}{$\begin{array}{l}\text { IGARCH }(1,1) \\
\end{array}$} \\
\hline \multirow[t]{2}{*}{ Confidence Level } & \multicolumn{3}{|c|}{ Short Position } & \multicolumn{3}{|c|}{ Long Position } \\
\hline & DQ & FR & ESF & DQ & FR & ESF \\
\hline $95 \%$ & 0.36556 & 0.94444 & 0.037049 & 0.51808 & 0.053968 & -0.032571 \\
\hline $97.5 \%$ & 0.92811 & 0.9754 & 0.04642 & 0.24084 & 0.019841 & -0.040275 \\
\hline $99 \%$ & 0.30806 & 0.99286 & 0.056746 & 0.11284 & 0.0055556 & -0.049368 \\
\hline \multicolumn{7}{|c|}{ GJR-GARCH $(1,1)$} \\
\hline \multirow{2}{*}{ Confidence Level } & \multicolumn{3}{|c|}{ Short Position } & \multicolumn{3}{|c|}{ Long Position } \\
\hline & DQ & FR & ESF & DQ & FR & ESF \\
\hline $95 \%$ & 0.24469 & 0.94286 & 0.037271 & 0.51808 & 0.053968 & -0.032571 \\
\hline $97.5 \%$ & 0.78665 & 0.97381 & 0.045565 & 0.32098 & 0.020635 & -0.039915 \\
\hline $99 \%$ & 0.65053 & 0.99127 & 0.056371 & 0.19277 & 0.0063492 & -0.048049 \\
\hline \multicolumn{7}{|c|}{$\begin{array}{l}\text { EGARCH }(1,1) \\
\end{array}$} \\
\hline \multirow[t]{2}{*}{ Confidence Level } & \multicolumn{3}{|c|}{ Short Position } & \multicolumn{3}{|c|}{ Long Position } \\
\hline & DQ & FR & ESF & DQ & FR & ESF \\
\hline $95 \%$ & 0.796 & 0.95159 & 0.037734 & 0.51808 & 0.046032 & -0.031729 \\
\hline $97.5 \%$ & 0.24084 & 0.98016 & 0.045357 & 0.086489 & 0.01746 & -0.036985 \\
\hline $99 \%$ & 0.30806 & 0.99286 & 0.054569 & 0.11284 & 0.0055556 & -0.047508 \\
\hline \multicolumn{7}{|c|}{$\operatorname{APARCH}(1,1)$} \\
\hline \multirow[t]{2}{*}{ Confidence Level } & \multicolumn{3}{|c|}{ Short Position } & \multicolumn{3}{|c|}{ Long Position } \\
\hline & DQ & FR & ESF & DQ & FR & $\mathrm{ESF}$ \\
\hline $95 \%$ & 0.24469 & 0.94286 & 0.037314 & 0.51808 & 0.053968 & -0.032514 \\
\hline $97.5 \%$ & 0.92811 & 0.9746 & 0.046219 & 0.41679 & 0.021429 & -0.039905 \\
\hline $99 \%$ & 0.30806 & 0.99286 & 0.056746 & 0.19277 & 0.0063492 & -0.048049 \\
\hline \multicolumn{7}{|c|}{ FIGARCH $(1,1)$} \\
\hline \multirow[t]{2}{*}{ Confidence Level } & \multicolumn{3}{|c|}{ Short Position } & \multicolumn{3}{|c|}{ Long Position } \\
\hline & DQ & FR & ESF & DQ & FR & $\mathrm{ESF}$ \\
\hline $95 \%$ & 0.038623 & 0.9373 & 0.036446 & 0.36556 & 0.055556 & -0.032508 \\
\hline $97.5 \%$ & 0.92811 & 0.9746 & 0.046739 & 0.41679 & 0.021429 & -0.03874 \\
\hline $99 \%$ & 0.8651 & 0.99048 & 0.053816 & 0.30806 & 0.0071429 & -0.047775 \\
\hline \multicolumn{7}{|c|}{ FIAPARCH $(1,1)$} \\
\hline Confidence Level & & ort Positi & & & Long Positi & \\
\hline & DQ & FR & $\mathrm{ESF}$ & DQ & FR & $\mathrm{ESF}$ \\
\hline $95 \%$ & 0.038623 & 0.9373 & 0.036446 & 0.36556 & 0.055556 & -0.032453 \\
\hline $97.5 \%$ & 0.92811 & 0.9746 & 0.046739 & 0.41679 & 0.021429 & -0.03874 \\
\hline $99 \%$ & 0.8651 & 0.99048 & 0.053816 & 0.30806 & 0.0071429 & -0.047775 \\
\hline
\end{tabular}

DQ corresponds to the $p$-value of the Dynamic Quantile test. .

FR shows the failure rate as per Kupiec's (1995) test.

ESF shows the expected shortfall when the VaR is breached. 
Table A.12: $\operatorname{GARCH}(1,1)$ rank per sector

\begin{tabular}{|l|c|c|c|c|c|c|}
\hline \hline \multicolumn{1}{|c|}{ Sector } & \multicolumn{3}{|c|}{ Short Positions } & \multicolumn{3}{c|}{ Long Positions } \\
& 0.95 & 0.975 & 0.99 & 0.95 & 0.975 & 0.99 \\
\hline Consumer Discretionary & 5 & 1 & 7 & 3 & 3 & 6 \\
Consumer Staples & 4 & 3 & 7 & 2 & 4 & 4 \\
Financials & 5 & 4 & 2 & 4 & 3 & 5 \\
Industrials & 6 & 1 & 5 & 6 & 5 & 4 \\
Energy & 5 & 5 & 5 & 5 & 5 & 5 \\
Information Technology & 4 & 4 & 1 & 5 & 3 & 4 \\
Telecommunications & 7 & 5 & 3 & 5 & 5 & 4 \\
Health & 5 & 1 & 4 & 5 & 1 & 3 \\
\hline Average Ranking & 5.125 & 3 & 4.25 & 4.375 & 3.625 & 4.375 \\
\hline \hline
\end{tabular}

Models ranked according to failure rate as per Kupiec (1995) test statistic.

Table A.13: IGARCH $(1,1)$ rank per sector

\begin{tabular}{|l|c|c|c|c|c|c|}
\hline \hline \multicolumn{1}{|c|}{ Sector } & \multicolumn{3}{|c|}{ Short Positions } & \multicolumn{3}{c|}{ Long Positions } \\
& 0.95 & 0.975 & 0.99 & 0.95 & 0.975 & 0.99 \\
\hline Consumer Discretionary & 3 & 3 & 4 & 2 & 2 & 3 \\
Consumer Staples & 6 & 2 & 2 & 5 & 7 & 5 \\
Financials & 5 & 7 & 4 & 3 & 3 & 7 \\
Industrials & 7 & 6 & 7 & 7 & 7 & 6 \\
Energy & 2 & 4 & 2 & 3 & 4 & 3 \\
Information Technology & 4 & 5 & 1 & 5 & 3 & 3 \\
Telecommunications & 4 & 3 & 7 & 4 & 7 & 6 \\
Health & 2 & 1 & 5 & 1 & 6 & 6 \\
\hline Average Ranking & 4.125 & 3.875 & 4 & 3.75 & 4.875 & 4.875 \\
\hline \hline
\end{tabular}

Models ranked according to failure rate as per Kupiec (1995) test statistic. 
Table A.14: GJR-GARCH(1,1) rank per sector

\begin{tabular}{|l|c|c|c|c|c|c|}
\hline \hline \multirow{2}{*}{ Sector } & \multicolumn{3}{|c|}{ Short Positions } & \multicolumn{3}{c|}{ Long Positions } \\
& 0.95 & 0.975 & 0.99 & 0.95 & 0.975 & 0.99 \\
\hline Consumer Discretionary & 6 & 6 & 4 & 6 & 4 & 5 \\
Consumer Staples & 6 & 5 & 6 & 1 & 4 & 7 \\
Financials & 5 & 2 & 4 & 7 & 7 & 5 \\
Industrials & 2 & 1 & 3 & 4 & 5 & 2 \\
Energy & 7 & 5 & 5 & 7 & 7 & 5 \\
Information Technology & 4 & 5 & 1 & 4 & 3 & 4 \\
Telecommunications & 6 & 7 & 3 & 7 & 3 & 1 \\
Health & 3 & 6 & 3 & 1 & 5 & 3 \\
\hline Average Ranking & 4.875 & 4.625 & 3.625 & 4.625 & 4.75 & 4 \\
\hline \hline
\end{tabular}

Models ranked according to failure rate as per Kupiec (1995) test statistic.

Table A.15: EGARCH(1,1) rank per sector

\begin{tabular}{|l|c|c|c|c|c|c|}
\hline \hline \multicolumn{1}{|c|}{ Sector } & \multicolumn{3}{|c|}{ Short Positions } & \multicolumn{3}{c|}{ Long Positions } \\
& 0.95 & 0.975 & 0.99 & 0.95 & 0.975 & 0.99 \\
\hline Consumer Discretionary & 1 & 3 & 1 & 1 & 1 & 1 \\
Consumer Staples & 1 & 1 & 5 & 7 & 1 & 5 \\
Financials & 1 & 1 & 2 & 1 & 2 & 1 \\
Industrials & 3 & 1 & 6 & 1 & 1 & 6 \\
Energy & 1 & 1 & 2 & 1 & 1 & 1 \\
Information Technology & 7 & 7 & 7 & 7 & 7 & 7 \\
Telecommunications & 1 & 1 & 2 & 1 & 1 & 6 \\
Health & 1 & 7 & 5 & 1 & 7 & 6 \\
\hline Average Ranking & 2 & 2.75 & 3.75 & 2.5 & 2.625 & 4.125 \\
\hline \hline
\end{tabular}

Models ranked according to failure rate as per Kupiec (1995) test statistic. 
Table A.16: APARCH(1,1) rank per sector

\begin{tabular}{|l|c|c|c|c|c|c|}
\hline \hline \multirow{2}{*}{ Sector } & \multicolumn{3}{|c|}{ Short Positions } & \multicolumn{3}{c|}{ Long Positions } \\
& 0.95 & 0.975 & 0.99 & 0.95 & 0.975 & 0.99 \\
\hline Consumer Discretionary & 6 & 7 & 4 & 5 & 4 & 7 \\
Consumer Staples & 4 & 5 & 2 & 4 & 4 & 2 \\
Financials & 3 & 5 & 6 & 4 & 3 & 4 \\
Industrials & 3 & 4 & 3 & 5 & 3 & 2 \\
Energy & 6 & 7 & 7 & 6 & 5 & 5 \\
Information Technology & 2 & 3 & 4 & 1 & 3 & 6 \\
Telecommunications & 4 & 3 & 3 & 6 & 2 & 2 \\
Health & 3 & 1 & 5 & 1 & 2 & 3 \\
\hline Average Ranking & 3.875 & 4.375 & 4.25 & 4 & 3.25 & 3.875 \\
\hline \hline
\end{tabular}

Models ranked according to failure rate as per Kupiec (1995) test statistic.

Table A.17: FIGARCH $(1,1)$ rank per sector

\begin{tabular}{|l|c|c|c|c|c|c|}
\hline \hline \multirow{2}{*}{ Sector } & \multicolumn{3}{|c|}{ Short Positions } & \multicolumn{3}{c|}{ Long Positions } \\
& 0.95 & 0.975 & 0.99 & 0.95 & 0.975 & 0.99 \\
\hline Consumer Discretionary & 2 & 2 & 2 & 6 & 6 & 4 \\
Consumer Staples & 2 & 3 & 1 & 6 & 2 & 2 \\
Financials & 2 & 2 & 1 & 2 & 1 & 2 \\
Industrials & 1 & 5 & 1 & 3 & 3 & 1 \\
Energy & 3 & 2 & 1 & 2 & 3 & 1 \\
Information Technology & 3 & 1 & 5 & 3 & 1 & 1 \\
Telecommunications & 2 & 2 & 3 & 2 & 3 & 4 \\
Health & 6 & 1 & 1 & 5 & 2 & 1 \\
\hline Average Ranking & 2.625 & 2.25 & 1.875 & 3.625 & 2.625 & 2 \\
\hline \hline
\end{tabular}

Models ranked according to failure rate as per Kupiec (1995) test statistic. 
Table A.18: FIAPARCH $(1,1)$ rank per sector

\begin{tabular}{|l|c|c|c|c|c|c|}
\hline \hline \multirow{1}{*}{ Sector } & \multicolumn{3}{|c|}{ Short Positions } & \multicolumn{3}{c|}{ Long Positions } \\
& 0.95 & 0.975 & 0.99 & 0.95 & 0.975 & 0.99 \\
\hline Consumer Discretionary & 3 & 3 & 2 & 3 & 7 & 2 \\
Consumer Staples & 2 & 5 & 2 & 3 & 3 & 1 \\
Financials & 3 & 5 & 6 & 4 & 6 & 2 \\
Industrials & 3 & 7 & 2 & 2 & 2 & 4 \\
Energy & 4 & 3 & 4 & 4 & 2 & 4 \\
Information Technology & 1 & 2 & 5 & 2 & 1 & 1 \\
Telecommunications & 3 & 5 & 1 & 2 & 5 & 2 \\
Health & 6 & 1 & 1 & 5 & 2 & 1 \\
\hline Average Ranking & 3.125 & 3.875 & 2.875 & 3.125 & 3.5 & 2.125 \\
\hline \hline
\end{tabular}

Models ranked according to failure rate as per Kupiec (1995) test statistic.

\section{Appendix B. Sector Results Discussion}

\section{Appendix B.1. Consumer Discretionary Index}

Table A.4 gives the out-of-sample VaR results for the Consumer Discretionary Index at different levels of confidence. All of the models analyzed show no remaining serial dependence in the variance structure from both a short and long position, as evidenced by the DQ $p$-values being larger than the relevant level of confidence. This finding is, however, more robust with regards to short positions than long positions with much smaller $p$-values observed in long positions across all models. When looking at the failure rates for short positions, it is evident that the EGARCH performs best at the $95 \%$ level followed by the FIGARCH, with the FIAPARCH and IGARCH tying for third place. However, all models underestimate the risk exposure as indicated by all the $95 \% \mathrm{FR}$ values being less than 0.95 . For a long trading position the EGARCH once again performs best with its FR being the closest to 0.05 , but all the models now overestimate the VaR. At a $97.5 \%$ level the EGARCH performs best for long positions whilst the GARCH model is preferred for short trades. The EGARCH once again does best at a 99\% level for both short and long positions with the FIAPARCH being the second best specification. In terms of ES, the results are relatively similar across all specifications. The ES values indicate that, on average, when the $99 \% \mathrm{VaR}$ is breached short trades can expect a loss of approximately $7 \%$ whilst for long trades the ES averages around 5.5\%. In summary, the VaR results for 
the consumer discretionary sector indicate the importance of accounting for asymmetries as evidenced by the EGARCH's performance.

\section{Appendix B.2. Consumer Staples Index}

As shown by table A.5 which displays the results for the consumer staples index, the DQ test statistic shows no remaining serial dependence in the variance structure. At a 95\% level, the FR shows the EGARCH as performing the best for short positions whilst the GJR-GARCH produces a perfect FR of 0.05 for long positions. The FIAPARCH also performs quite well in both short and long positions, ranking second in estimating both tails of the distribution at a $95 \%$ level. When looking at the VaR results foor the $97.5 \%$ level, the EGARCH performs the best in both long and short positions. The FIGARCH ranks second in terms of long positions at a $97.5 \%$ level whilst the IGARCH does the same for short positions. It is interesting to note that all the other models significantly underestimate risk for long positions at a 97.5\% level, and overestimate risk for short positions. This can be seen from the FR values trending around 0.02 and 0.978 for long and short positions respectively. At a 99\% level, the FIGARCH has a short FR closest to 0.99 out of the models, with the FIAPARCH displaying the same result regarding long FRs. Additionally, the FIAPARCH ranks second for the $99 \%$ short FR. With regards to ES performance, when the $99 \%$ VaR for short trades is breached investors can expect losses in the region of $4.5 \%$ whilst long trades are expected to lose approximately $4 \%$. The results from the consumer staples sector complement the findings from table A.4 in that it highlights the importance of accounting for asymmetries in addition to the robustness of the FIAPARCH specification in modelling both short and long risk exposure.

\section{Appendix B.3. Financials Index}

Table A.6 shows the estimation results for the financials index. For this portfolio of assets, the DQ statistics are less homogenous across trading positions. Specifically, there is evidence of remaining serial dependence for short positions in the IGARCH and APARCH models. No such concerns exist for long positions. When it comes to failure rates, the EGARCH and FIGARCH perform the best overall at the 95\% and $97.5 \%$ level for both long and short positions. In comparison the GARCH, IGARCH, GJR-GARCH, and APARCH models significantly underestimate risk exposure whereas the FIAPARCH model overestimates short risk at a 95\% level. When looking at the $99 \%$ level, the IGARCH and GJR-GARCH FRs comes closest to 0.01 for 
short positions whilst the EGARCH does best for long positions. Regardless, all of the model specifications perform relatively poorly in estimating risk exposure in the financials index. This conclusion stems from the fact that the models either overestimate or underestimate risk significantly at all confidence levels. Nevertheless the EGARCH specification seems the most appropriate, indicating toward the importance of accounting for asymmetries when modeling volatility.

\section{Appendix B.4. Industrials Index}

The dynamic quantile test statistics for the industrials index shows no remaining serial correlation in any of the models, bar the IGARCH, as indicated by table A.7. The VaR estimates' performance in terms of failure rates show the FIGARCH as producing an FR closest to 0.95 for short positions at a $95 \%$ level; however it performs poorly for long positions where the EGARCH ranks best. The FIAPARCH once again reveals the consistency property established in the previous results, showing FRs of 0.955 and 0.045 for long and short positions at a 95\% level. When we shift out attention to the 97.5 percentile, the GARCH, IGARCH, and EGARCH models perform best for short positions, with the EGARCH also ranking best in terms of long positions. At a 99\% level, the FIGARCH produces very accurate VaR estimates as depicted by FRs of 0.9913 and 0.0103 for short and long positions respectively. In terms of expected shortfall, the estimates are relatively consistent across models and confidence levels, indicating an expected loss of approximately $4.8 \%$ for short positions and $4.6 \%$ for long positions when the $99 \% \mathrm{VaR}$ is breached. In summary, the results from A.7 indicate the importance of accounting for fat-tails in the distribution, especially at higher confidence levels. Also asymmetrical controls are deemed necessary as indicated by the EGARCH's results at a $95 \%$ level.

\section{Appendix B.5. Energy Index}

The energy index's VaR results are contained in table A.8. These indicate a large degree of heterogeneity, across both models and trading positions, in the different specifications' ability to remove serial dependence from the variance structure. Specifically, only the EGARCH and FIGARCH models are able to reject the hypothesis of serial dependence at all confidence levels and trading positions. This is reflected in the failure rates of the models, with only the EGARCH and FIGARCH producing estimations that are relatively close to the relevant percentiles for both short and long positions at a $95 \%$ 
level. This narrative doesn't change when we concern ourselves with the 97.5 and 99 percentiles, except for the fact that the FIGARCH is outperformed by the FIAPARCH for long trading positions at a $97.5 \%$ level. Nevertheless, the FIGARCH's FR for short positions at the $99 \%$ level is very close to the desired 0.99 level whilst the EGARCH does best at predicting long tail risk at the $99 \%$ level. Even so, all the models overestimate short tail risk and underestimate long tail risk. The expected shortfall measures also exhibit a high degree of variation between models. Due to their high ranking in terms of FR performance, we utilize the ESF statistics generated by the EGARCH and FIGARCH models. These indicate losses in the region of $4.8 \%$ for short positions and $4.1 \%$ for long positions when the $99 \%$ VaR is breached.

\section{Appendix B.6. Information Technology Index}

Table A.9 below contains the results from the VaR estimation on the information technology index. Interestingly the DQ stats from table A.9 show the EGARCH model as being the least appropriate specification, revealing a statistically significant degree of serial persistence in the variance process. Furthermore, the FR and ESF for the and 99\% level on short trades could not be computed for the EGARCH. It is also evident that most of the models struggle to reject the hypothesis of serial correlation being present at the 97.5\% level, but not at the $95 \%$ or $99 \%$ levels. Turning to failure rates, the estimates show FIAPARCH as performing best in predicting VaR for short trades at the $95 \%$ level, whilst the APARCH shows the best FR for long trades at the same level of confidence. At a $97.5 \%$ level of confidence, the FIGARCH provides the best VaR for short trades whilst the FIAPARCH ranks first in terms of FR for long trades. Similarly, at a $99 \%$ level, the FIAPARCH displays an FR closest to 0.01 for long trades witht he GARCH, IGARCH, and GJR-GARCH performing best for short positions at the same level of confidence. From the above we would therefore conclude on the FIAPARCH as providing the best overall results; however all the specifications either underestimate long tail risks or overestimate short tail risks. Table A.9 also shows an expected shortfall of around $7 \%$ for short trading positions, and $6 \%$ for long trading positions, when the $99 \%$ VaR is breached. In summary, the results from table A.9 show long memory models to offer the best VaR estimates. 


\section{Appendix B.\%. Telecommunications Index}

Table A.10 contains the VaR results from the telecommunications index. The DQ stats reveal an inability in most of the models to remove serial dependence in the short position tails. In fact, only the EGARCH is able to reject the null of serial correlation at all confidence levels as well as for both trading positions. The FIGARCH also does well in this respect, except for short trades at the $95 \%$ level. It is therefore not surprising that the EGARCH provides a FR closest to the deisred level for both short and long positions at the $95 \%$ level. The FIGARCH and FIAPARCH models come a close second at this level of confidence, with the showing FRs of approximately 0.965 and 0.0452 for the short and long positions respectively. From table A.10 it is also evident that the EGARCH outperforms all the other models at $97.5 \%$ for both trading positions; however at 99\%, the GJR-GARCH provides the best VaR estimates for short and long trades. As before, all the models overestimate short tail risks and underestimate long tail risks. From an expected shortfall perspective, the GJR-GARCH model shows an ES of $5.4 \%$ for short trades when the $99 \% \mathrm{VaR}$ is breached, correspondingly the long ESF is estimated at around 5\%. Table A.10 therefore indicates toward asymmetries being the most important factor to control for in volatility specifications that aim to estimate VaR.

\section{Appendix B.8. Health Index}

The last set of VaR estimations concerns the health index with the results contained in table A.11. For this returns series, the DQ statistics show that all serial persistance has been removed from the variance process, both in long and short positions. From a VaR accuracy perspective, the results show the EGARCH to perform best on short positions at a $95 \%$ level whilst the IGARCH, GJR-GARCH, and APARCH models rank first for long positions at the same percentile. At the $97.5 \%$ level, the best models for short positions are the GJR-GARCH, APARCH, FIGARCH, and FIAPARCH specifications; producing FRs that are only 0.0004 units away from the optimum of 0.975 . On the long side, the GARCH does best at a $97.5 \%$ level, followed closesly by the APARCH, FIGARCH, and FIAPARCH models. Turning our attention to the $99 \%$ level, the FIAPARCH and FIGARCH models emerge as the most applicable specification with their FRs being extremely close to the desired 0.99 level for short trades. That being said, their long VaR at $99 \%$ underestimates risk as shown by the FR of 0.007 ; however these specifications remain the best performers out of the set of models used in this analysis. 
The results from table A.11 also indicate that the models fared better at estimating VaRs for short positions as opposed to long trades. This can be seen when comparing the FRs for short and long trades within each model. It is evident that the short FRs are on average closer to the required level than those for the long positions. Looking at the expected shortfall when the VaR is breached, we see homogeneity across the models with a $99 \%$ VaR breach resulting in an expected loss of approximately $5.3 \%$ for short trades and $4.8 \%$ for long trades. In summary, the health index VaR estimates show long memory and asymmetries as crucial factors to control for in VaR analysis. 